Portland State University

PDXScholar

Fall 2017

\title{
Hydrological Patterns and the Effects of Land Use on TSS Concentrations and Yields in the McCarthy Creek Watershed, Portland, Oregon
}

David Farmer

Portland State University

Follow this and additional works at: https://pdxscholar.library.pdx.edu/mem_gradprojects

Part of the Environmental Studies Commons, and the Water Resource Management Commons Let us know how access to this document benefits you.

\section{Recommended Citation}

Farmer, David, "Hydrological Patterns and the Effects of Land Use on TSS Concentrations and Yields in the McCarthy Creek Watershed, Portland, Oregon" (2017). Environmental Science and Management Professional Master's Project Reports. 29.

https://pdxscholar.library.pdx.edu/mem_gradprojects/29

https://doi.org/10.15760/mem.10

This Project is brought to you for free and open access. It has been accepted for inclusion in Environmental Science and Management Professional Master's Project Reports by an authorized administrator of PDXScholar. Please contact us if we can make this document more accessible: pdxscholar@pdx.edu. 


\title{
Hydrological Patterns and the Effects of Land Use on TSS Concentrations and Yields in the McCarthy Creek Watershed, Portland, Oregon
}

\author{
By David Farmer \\ Submitted to Fulfill Degree Requirements for the \\ Master of Environmental Management Program \\ of the Portland State University \\ Department of Science and Management.
}

Thesis Committee:

Dr. Jennifer Morse

Dr. Joseph Maser

Scott Gall (MS)

\section{Portland State University}

$11 / 20 / 2017$ 


\section{Table of Contents}

\section{Abstract}

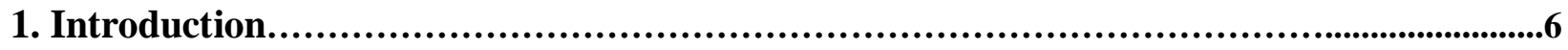

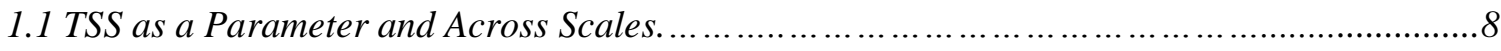

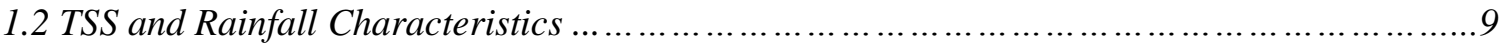

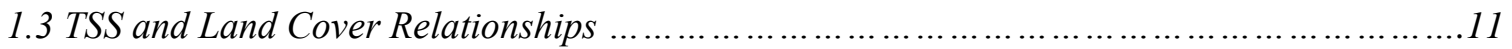

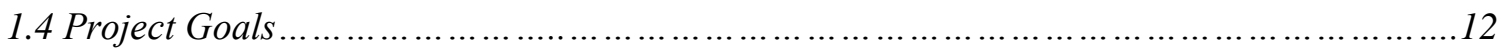

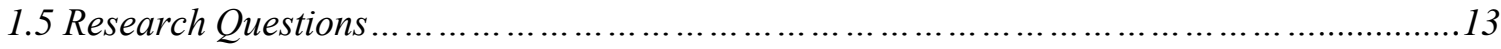



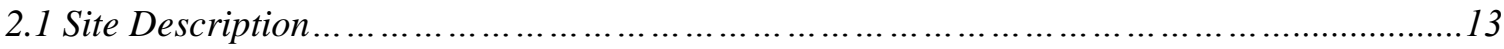

2.2 Field Measurements - Spatially Extensive Sampling ........................................16

2.3 Field Measurements - Time Series Sampling................................................... 18

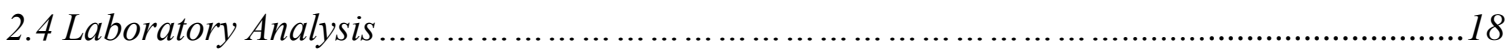

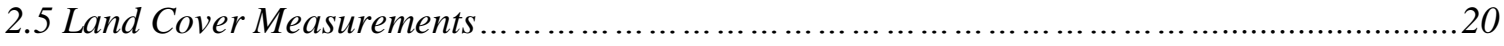

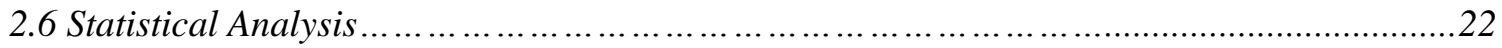

2.6.1 Spatially Extensive TSS Concentration and Peak Flow Yield Sampling.................22

2.6.2 Regression Analysis of TSS Concentrations and Rainfall Characteristics.............23

2.6.3 Regression Analysis of Time-Series Trends in TSS Concentrations....................24

2.6.4 Spatial Analysis of TSS Concentrations as a Function of Land Cover...................24

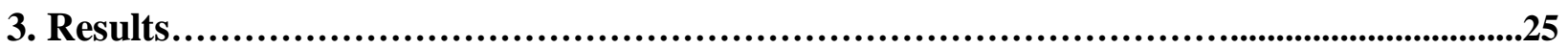

3.1 Spatially Extensive TSS Sampling During Storm Events .....................................25

3.1.2 Spatially Extensive ANOVA and T-test Results................................29

3.2 Spatially Extensive Sampling Estimated TSS Yields During Storm Events ...........................30

3.2.1 Spatially Extensive Estimated TSS Yields ANOVA Results..............................31

3.3 Linear Regression of Spatially Extensive Data During Storm Events .............................33

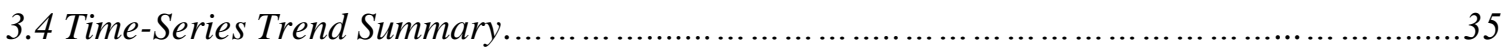

3.4.1 Time-Series GLS Model Results........................................................

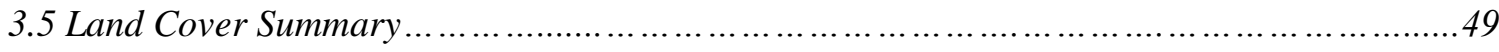

3.5.1 Land Cover OLS and Spatial Regressions for Mean LogTSS Concentrations for...41 Tributary and Mainstem Sampling Locations

3.5.2 Land Coverage OLS and Spatial Regressions and Peak Flow Yields for. 42 Tributary and Mainstem Sampling Locations 


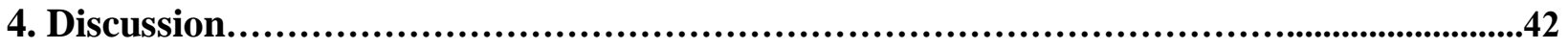

4.1 Spatial Extension TSS concentrations and Yields During Storm Events ..........................42

4.2 Rainfall Characteristics, TSS Concentrations, and TSS Yields ...............................45

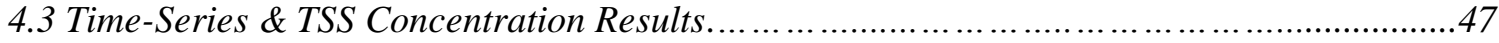

4.4 Land Use Cover \& TSS Concentrations and Yields...............................................49



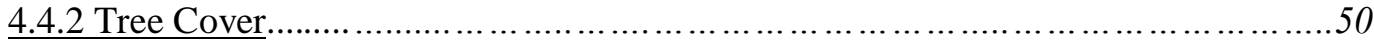



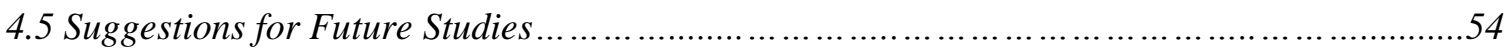

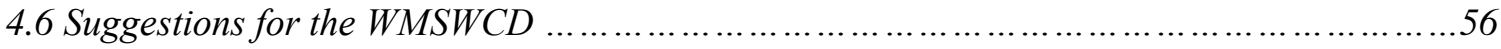

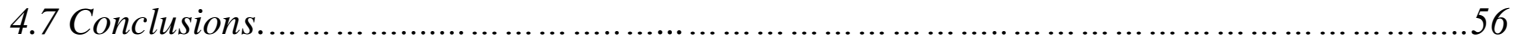








\section{Acknowledgements}

I would like to give my sincerest thanks to Dr. Jennifer Morse for agreeing to be my adviser and both overseeing, providing logistics, lab materials \& space, and for helping to facilitate my project. I also thank Ben Shetterly and Erin Looper of the Morse Lab for assisting me in my data analysis questions.

Also, I thank Scott Gall for being my point of contact person for my Community Partner, the West Multnomah Soil \& Water Conservation District, and for providing me materials and data that made this project possible.

Many thanks to Dr. Heejun Chang for providing me with the ISCO 6700 Autosampler and Adam Mosburg for answering all of my GIS related inquiries.

Last but not least, I would like to thank my wife Michelle Mireille Wells for her constant support throughout the most difficult portions of this project. 


\begin{abstract}
The spread of impervious surface areas and the reduction of tree canopy via urbanization has numerous water quality impacts on Pacific Northwest watersheds. One such impact is elevated levels of Total Suspended Solids (TSS) in run-off during storm events, particularly in steep, forested watersheds undergoing urbanization. This project was developed in collaboration with the West Multnomah Soil and Water Conservation District and focused on the McCarthy Creek Watershed, as a case-study watershed located in Portland, OR. The study aimed to identify elevated TSS concentrations and yields during storm events on both mainstem and tributary sampling locations, establish the relationship between TSS and rainfall variables (rainfall depth, rainfall intensity, and rainfall duration), and determine the most significant land cover variables as predictors of TSS based on delineated sub-watersheds in McCarthy Creek. These data were collected through a combination of grab sampling, hourly autosampling, and GIS analysis during the course of the later winter and early spring. All of the sampling locations exceeded informal TSS thresholds during storm events, but no statistically significant differences were found in TSS concentrations or yields for any of the sampling locations. Rainfall depth was the most significant predictor of TSS concentrations in the mainstem locations and autosampler results, while rainfall intensity was the most significant predictor of TSS in tributary sampling locations. Land cover regression models did not uncover any significant relationships between TSS and land cover variables. McCarthy Creek Watershed may so spatially homogenous in terms of land cover that TSS concentrations are similar throughout the watershed, resulting in low variance explained by land cover variables.
\end{abstract}




\section{Introduction}

As urban populations in the Pacific Northwest continue to grow and expand, the increase in adverse effects of urbanization on rivers and streams will follow. The impacts of urbanization on instream and riparian environments are numerous, negative, and interacting (Hatt et al. 2004). Several biological issues include reduction of riparian wildlife habitat and impaired fish habitat due to soluble chemical pollutants and physical channelization (Allan 2004; Biollota and Brazier 2008). Some hydrological problems from urbanization include increased runoff, higher peak discharge, higher peak flow, more rapid rising and fall limbs in the form of "flashy" hydrographs, and higher erosion rates of stream banks and beds (Dodds and Whiles 2004; Franczyk and Chang 2009; Bell et al. 2016). Lastly, the effects of urbanization severely degrade water quality during base-flow and especially during storm events, due to deforestation and the expansion of impervious surfaces (Schoonover et al. 2007; Bell at al. 2016; Coulter et al. 2004; Chen and Change 2014).

The reduction of tree canopy, or tree coverage and the increase in impervious surfaces due to urbanization have numerous negative impacts on the water quality of streams in the Pacific Northwest. The mechanisms involved are the losses of lateral interception of precipitation from tree canopies, horizontal filtration by the trees physically blocking inflow, and infiltration during precipitation events that result in higher run-off and pollutant build up (Vogel and Moore et al. 2017; Palmer et al. 2007). These impacts are especially acute during storm events, when higher runoff velocity is the main method of transport of a variety of pollutants downstream, increasing bed and bank erosion, and other effects from increased peak flow (Bell et al. 2016; Gomi et al. 2005).

The specific consequences of the interaction between changes in land cover and hydrology on water quality during storm events are numerous. One is the mobilization of heavy metals, such as lead and mercury from point source pollution or atmospheric deposition, in runoff during storm events due to the lack of tree canopy and deposition on impervious surface areas (Murphy et al. 2015a; Vogel and Morre 2017; Murphy et al. 2015b). Additionally, eutrophication in downstream waters can result from 
excess nitrogen, phosphorus, and other nutrients in storm water (Hatt et al. 2004; Singh and Chang 2014), leading to harmful algal blooms and lower dissolved oxygen. Particulates and sediment from run-off from construction sites and increased bank and bed erosion are a problem as well, as sediment deposition can degrade habitat for macroinvertebrates and especially salmon spawning (Biollota and Brazier 2008; Vogel and Moore 2017).

Increases in particulates and suspended sediment are problematic throughout many urban and rural watersheds that have undergone significant urbanization (Coulter et al. 2004; Jordan et al. 2014). Total Suspended Solids (TSS) is a water quality parameter that has been found to be particularly affected by urbanization and land use changes. Increased urbanization often leads to higher TSS concentrations ${ }^{1}$, $\operatorname{loads}^{2}$, and yields ${ }^{3}$ in storm-water runoff, depending on the severity and age of development in a specific watershed at almost all spatial scales (Chen and Chang 2014; Schoonover et al. 2007; Coulter et al. 2004; Singh and Chang 2004). Higher TSS concentrations can compound other water quality issues mentioned before, as metals and excess nutrients can bind to suspended particles, leading to heavy metal exposure or provide a mechanism for increased eutrophication (Rossi et al. 2005; Biollota and Brazier 2008).

There is a clear need to remedy water quality issues such as elevated TSS concentrations and yields for streams that are experiencing urbanization. In many regions, many agencies and non-profits conducted watershed restoration efforts with a focus on revegetation of riparian areas to increase tree cover. The relationship between tree cover and a variety of pollutants was found to be negative in numerous studies, indicating that an increase in tree canopy should reduce pollutant loads to streams during storm events (Jordan et al. 2014; Bell et al. 2016; Uwimana et al. 2017). Additionally, the increase in infiltration provided by restoration can reduce pollutants in downstream flow and reduce peak flow (Jarden et al. 2016). Many organizations in the Pacific Northwest (PNW) such as the West Multnomah Soil \& Water Conservation District (WMSWCD) have embraced local and regional riparian restoration

\footnotetext{
1 TSS Concentrations Units: $\mathrm{mg} / \mathrm{L}$

2 TSS Loads Units: Tons

3 TSS Yields Units: Tons/Acre/Year
} 
projects that involve the planting of native plants, with the goal improving water quality via preventing erosion, trapping sediment, and increasing infiltration rates on the landscape (Palmer et al. 2007; Gall 2015).

The McCarthy Creek Watershed has been targeted for riparian restoration efforts by the WMSWCD due to the level of stream degradation resulting from current and ongoing forestry practices, rural development, and in-stream modifications (MCRS 2010 and Gall 2015). This small watershed was targeted for restoration efforts due to high summer temperatures and low dissolved oxygen (Gall 2015 and MCRS 2010). Additionally, the results from macroinvertebrate surveys near the outlet indicate that McCarthy Creek has high sediment loading due to the absence of taxa that are sensitive to high sediment loading (Patterson 2010; Gall 2016; Dodds and Whiles 2004; Gall 2015; MCRS 2010).

Sediment problems have been identified throughout McCarthy Creek and other similar water bodies within the adjacent Forest Park/Willamette River Watershed area of Portland, Oregon (BES 2015), but the sources of high TSS within the watershed have not been determined. Since tributaries with high flow and differences in mainstem section erosion rates can each contribute to high particulate loads, and given the historical land use and land cover changes and known sediment issues from the WMSWCD macroinvertebrate study in the watershed, identifying sections of McCarthy Creek that are the most impaired in terms of TSS would be helpful in informing future restoration efforts (Morris et al. 2014; Zapico et al. 2017).

\subsection{TSS as a Parameter and Across Scales}

TSS concentrations and yields are often used as an integrative water quality parameter because TSS reflects turbidity and organic and inorganic materials in the water column, including in-stream sediment, detritus, and other particulates (Singh and Chang 2014; Biollota and Brazier 2008; RosadoBerrios and Bouldin 2016; BES 2015). Pollutants of interest, such as fecal coliforms, nutrients, and 
heavy metals, tend to bind to particles and so are often associated with TSS (Chen and Chang 2014; Biollota and Brazier 2008; Vogel and Moore 2017). Although the severity of TSS damage to in-stream ecosystems such as smothering of salmonid Redds depends on characteristics such as particle size distribution, any elevated concentrations and yields are problematic to water quality (Biolotta and Brazier 2008; Vogel and Moore 2017). Therefore, it is a regulated water quality parameter under a variety of agencies from the local to federal level (Dodds and Whiles 2004; BES 2015).

High TSS values have been found to be problematic throughout the United States across a range of spatial scales. At the continental scale, rivers in western and northern Ecoregions of the United States were found to have the highest TSS concentrations during both base-flow and storm events in both urbanized and forested watersheds (Dodds and Whiles 2004). Studies at the regional scale are most common, with the goal of comparing watersheds by land cover, land use, or differences in impervious surface types. Fewer TSS studies focus at finer scales that would be more useful to local land management agencies.

Regional studies have concluded that development plays an important factor in elevating TSS concentrations compared to more forested streams during storm events (Coulter et al. 2004; Vogel and Moore 2017; Chen and Chang 2014; Jordan et al. 2013). At the more site-specific level, the degree of imperviousness, such as concrete roads versus porous pavement, has a positive correlation with high TSS values in runoff (Charters et al. 2015; Murphy et al. 2015b; Zhang et al. 2016). Most of the published results on the relationship between TSS and land cover/land use at the regional scale are consistent with findings at finer scales (Hatt et al. 2004; Mallin et al. 2009; Borris et al. 2014).

\subsection{TSS and Rainfall Characteristics}

It has been well established in the water quality literature that TSS concentrations and yields generally increase with increasing flow during storm events (Mallin et al. 2009; Vogel and Moore 2017; 
Chen and Chang 2014). Often, higher run-off and peak flow during storm events are proportional to higher TSS concentrations and higher yields (Mallin et al. 2009; Murphy et al. 2015a; Sun et al. 2015; Goore Bi et al. 2015; Zhang et al. 2014). The rainfall storm event variables that influence higher peak flows and run-off are rainfall depth $(\mathrm{RH})^{4}$ or total accumulated rainfall height for the duration of a storm, rainfall duration $(\mathrm{RD})^{5}$ or the total amount of time that a storm lasts, and rainfall intensity $(\mathrm{RI})^{6}$ or the total amount of rain given by RH divided by storm duration (Borris et al. 2014 and Goore Bi et al. 2015). These in turn influence TSS concentrations to varying degrees (Borris et al. 2014).

Out of the three rainfall characteristics, RH and RI were found to have the highest correlation with TSS, although a handful of studies such as Murphy et al. (2015a) found RD to be more highly correlated with TSS concentrations. Conversely, studies that compared RH and RI directly to one another reached different conclusions; for example, Goore Bi et al. (2015) found that RH was strongly correlated with TSS event mean fluxes, while RI was more strongly correlated with TSS event mean concentrations. Other studies have found that RI was positively correlated to TSS concentrations, though only the first flush period after extensive antecedent dry days were studied (Zhang et al. 2014; Vogel and Moore 2016). In a study that focused exclusively on impervious surface areas, RI was found to have a stronger relationship with TSS concentrations rather than RH (Murphy et al. 2015b). In contrast, Borris et al. (2014) and Malin et al. (2009) found that TSS event loads in a sub-watershed have a higher correlation with RH rather than RI across multiple small sub-basins northern Sweden and North Carolina during the entirety of a rainy season. Although all are important, the effects of RH, RI, and RD on TSS concentrations, loads, and yields vary in the literature and are likely based on variations in land cover and scale.

\footnotetext{
${ }^{4} \mathrm{RH}$ Units: Inches of rainfall per storm

${ }^{5}$ RD Units: Total hours of a storm

${ }^{6}$ RI Units: Inches of rainfall per storm / Total hours of a storm
} 


\subsection{TSS and Land Cover Relationships}

Different studies have different conclusions on TSS during storm events and watershed, subwatershed, and small area land cover or land use: Some state that impervious surfaces and urban area land use are weakly correlated to TSS concentrations while others reach the opposite conclusion. Numerous studies concluded that higher TSS concentrations and loads were present in streams surrounded by all forms of impervious surfaces and adjacent areas under "Urban" land use (Chen and Chang 2014; Schoonover et al. 2007; Bell et al. 2016). In contrast, other studies had found that streams near lands with high impervious surface areas and Urban land use had lower TSS concentrations and loads when compared to areas classified as Agriculture, Mixed, or Suburban (Hatt et al. 2004; Coulter et al. 2004; Valtanen et al. 2015; Mallin et al. 2009). In fact, numerous studies point towards land under agriculture as producing the highest TSS concentrations and yields (Jordan et al. 2013; Mallin et al. 2009; Singh and Chang 2014). Singh and Chang (2014) speculate that this is likely due to the high supply of particulate matter in Agricultural areas that undergo constant disturbance given that TSS consists of both organic and inorganic material. Shifts from agricultural practices to fallowing fields or forestry may have a negative effect on TSS concentrations and yields (Kreilling and Houser 2016).

The debate over the of the effects of urban land use and impervious surface area to elevated TSS concentrations and yields during storm events could be due to the time lag between installation and a respective study. TSS concentrations and loads are highly problematic during initial conversion and construction due to high rates of erosion from exposed soil (Dodds and Whiles 2004; Jordan et al. 2013; Sun et al. 2015). Long after construction, impervious surface areas and urban lands may become sediment supply limited as erosion ceases to be a force (Dodds and Whiles 2004; Singh and Chang 2014.) The main source of TSS within these areas would become build-up from runoff deposits, atmospheric deposition, and leakage from sewage (Vogel and Moore 2017; Murphy et al. 2015a). Therefore, the age and degree of urbanization in a watershed is extremely important when attempting to determine the relationships between impervious surface areas, urban land use, and TSS. 
Tree canopy is mostly assumed to have a negative effect on TSS concentrations and yields.

Jordan et al. (2013) had found that increasing tree canopy appeared to have a negative relationship with TSS with $33 \%$ forestry cover being the threshold in which TSS concentrations are reduced during storm events (Dodds and Whiles 2004; Rosado-Berriors and Bouldin 2016). The positive effects of tree canopy and TSS/Sediment control is especially prevalent in literature dealing with site level riparian area restoration and during implementation of green storm-water structures (Gomi et al. 2005; Jarden et al. 2015). It was shown that green infrastructure including both Riparian area restoration and green stormwater management structures decrease TSS concentrations and yields (Jarden et al. 2016).

However, studies that focus on the effects of impervious surfaces and urban land use at the watershed scale often do not use tree canopy directly within their analysis. Rather, many of the experimenters assume low impervious surface/urban areas is equivalent to high tree canopy if not classified as Agriculture (Mallin et al. 2009). When canopy is measured directly in a study, the effects of deforestation and increased TSS concentrations and yields are the main focus rather than the effects of improving tree canopy on reducing TSS concentrations and yields (Jordan et al. 2013). This is likely due to the fact that restoration efforts are relatively new and still need more time for establishment before the effects of tree canopy and TSS can be observed. (Jordan et al. 2013; Singh and Chang 2014).

\subsection{Project Goals}

The WMSWCD has a clear need to determine sources of high sediment/TSS in McCarthy Creek to focus their restoration efforts in order to save time and resources. To fulfill this need, I collaborated with WMSWCD to 1) determine the location of any significant TSS sources and yields in the mainstem and tributary locations in the McCarthy Creek watershed; 2) find predictive relationships between rainfall variables under different time periods and TSS concentrations and yields for mainstem and tributary 
locations; and 3) determine the effects of different land cover types on TSS concentrations and yields to help guide the WMSWCD in establishing priority restoration locations.

\subsection{Research Questions}

1. What sections of the mainstem exceed the City of Portland Bureau of Environmental Services informal threshold of $43 \mathrm{mg} / \mathrm{L}^{7}$ and have significantly higher TSS concentrations and yields during storm events?

2. Which tributaries exceed informal thresholds and have significantly higher TSS concentrations and yields during storm events?

3. Which rainfall variable [Rainfall Depth (RH), Rainfall Intensity (RI), and Rainfall Duration (RD)] has the best relationship in predicting TSS concentrations and yields?

4. What land cover values (percentage impervious surface ${ }^{8}$, percentage tree canopy ${ }^{9}$, and mean basin slope ${ }^{10}$ ) are associated with higher average TSS concentrations and yields for mainstem sampling points and tributaries in the watershed during storm events? Is there a difference for various rainfall time periods?

\section{Methods}

\subsection{Site Description}

McCarthy Creek is a small watershed that lies south of the town of Scappoose, Oregon, with a mainstem length of 8396 meters with perennial flow, 15 known ephemeral and permanent tributaries, that flows north before emptying into the Multnomah Channel of the Columbia River (N45³9'04.711" W122 50'59.865"; Figure 1). The climate is a marine West Coast environment that is characterized by

\footnotetext{
${ }^{7}$ As informed by the Portland Bureau of Environmental Services and by the Oregon Department of Environmental Quality for the TMDL for TSS established for the Lower Willamette Subbasin; this was the TSS concentration for a stream for an informal "Impaired" designation used for the Watershed Health Index by BES. This was derived from both combined storm and baseline samples (PAWMAP 2015; ODEQ 2006)

${ }^{8}$ Percentage impervious surface area in a $3 \times 3 \mathrm{~m}$ pixel, including driveways, roofs, and roads

${ }^{9}$ Percentage tree canopy in a $3 \times 3$ pixel, accounting for only tree tops

${ }^{10}$ Average slope for a delineated basin in degrees
} 
dry summers to wet winters with high amounts of precipitation that mostly consists of constant, lowintensity rain (Singh and Chang 2014). The majority of McCarthy Creek itself runs alongside and downhill of Cornelius Pass Road, which is heavily used by freight trucks and other traffic from Highway 30 (Figure 1; Scott Gall, personal communication, 2016). The combined factors of climate and road location result in surface runoff that flows from the road into the stream from culverts during storm events.

The headwaters are located in the McCarthy Creek Natural Area that is managed by Oregon Metro for habitat enhancement (Figure 1; Metro Parks and Nature 2016). However, most of the surface area of the watershed is privately owned and has gone through multiple historical land use changes from old growth forest to logging, mining, and residential. These changes increased impervious surface areas via driveways, roads, and rooftops by $1.49 \%$ while decreasing tree canopy to $70.7 \%$ over time, as is apparent from the National Land Cover Database (NLCD) 2011 data collection (Figure 2).

Several stretches of McCarthy Creek and its tributaries have highly impaired water quality as indicated by elevated temperatures, low dissolved oxygen, few to no sensitive macroinvertebrate taxa, and high percentage fine sediments (Multnomah County 2009). Other smaller watersheds adjacent to McCarthy Creek have experienced similar issues. In particular, the Portland Area Watershed Monitoring and Assessment Program (PAWMAP) had found that Willamette streams south of McCarthy Creek had TSS concentrations that were above $25 \%$ of the BES thresholds for baseline values (Multnomah County 2009; PAWMAP 2015).

In response to the impacts of land use changes on water quality, over 25 properties (or $0.38 \%$ of all riparian acres) within the watershed have undergone some form of revegetation since 2009 for a variety of purposes including green storm-water management and upland habitat enhancement. These projects span several years, with multiple steps that include invasive species removal, native plant installation, and repeated invasive species maintenance as a remedy to loss of habitat and water quality 
issues. Several older and established projects exist in the study area and new projects are added every year.

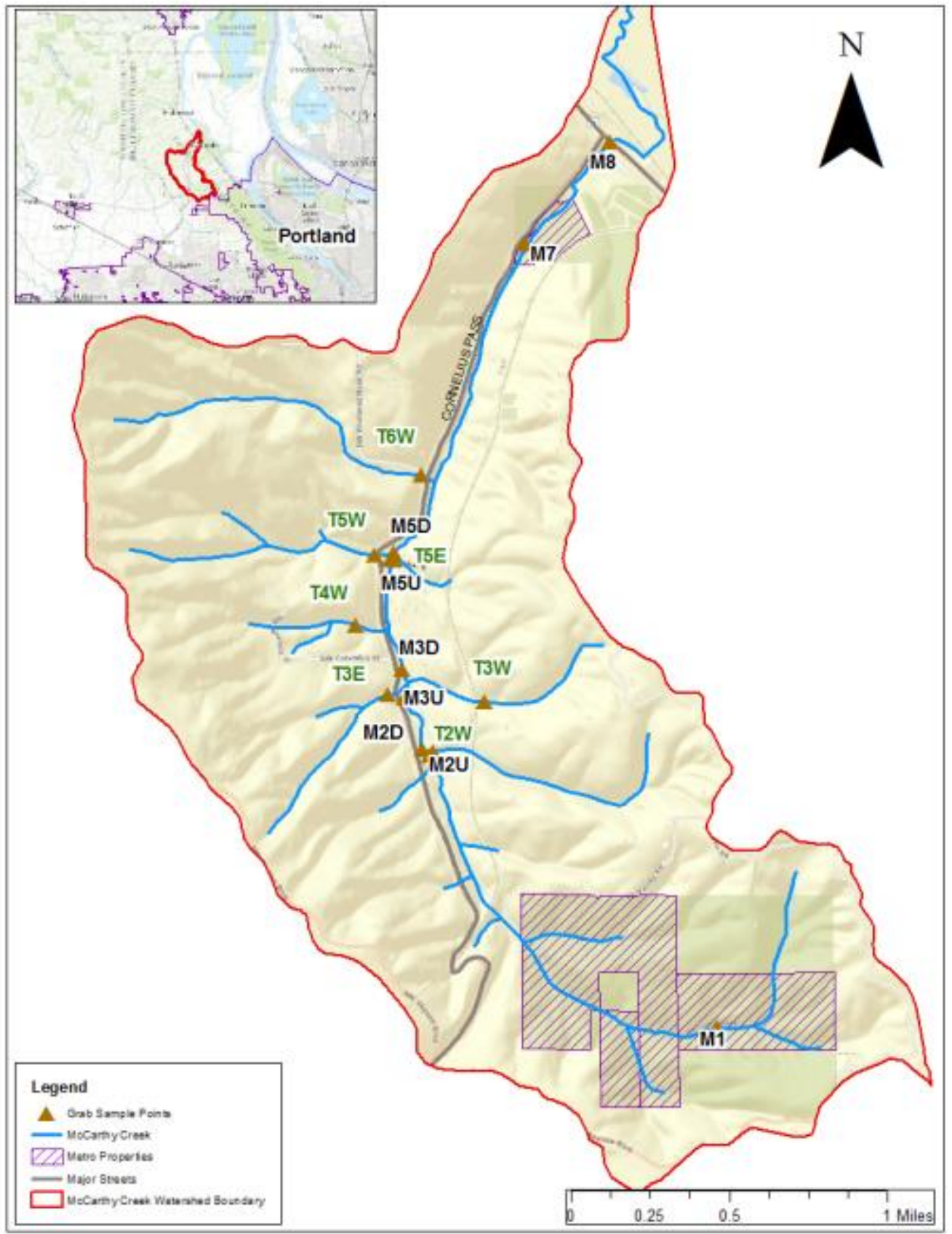

Figure 1: Geographic location and Sampling locations of the McCarthy Creek Watershed. Sampling locations with an "M" is a mainstem sampling point $(n=9)$, while " $T$ " represents tributary sampling points $(n=7)$. Locations were chosen based on landowner permission and ease of access. River flow orients from South to North. The autosampler was installed at M7, near the assigned grab sample. The McCarthy Creek stream and boundary data was provided by the West Multnomah Soil \& Water Conservation District. 


\subsection{Field Measurements - Spatially Extensive Sampling}

The field portion of the study focused on determining the geographical distribution of TSS $(\mathrm{mg} / \mathrm{L})$ concentrations during storm events throughout the watershed during the same narrow window of time under different cumulative rainfall scenarios. These storms were defined as requiring cumulative rainfall greater than 0.15 inches during the course of 24 hours as predicted by using the "Weather Underground" forecasting tool (https://www.wunderground.com/forecast/us/or/portland). Although some other studies had a minimum of a few hours without rain between storms, I set a minimum of at least 6 hours of dry conditions prior to attempting another sample (Mallin et al. 2009; Sun et al. 2015).

A total of eight storm events were sampled between February and June 2017 for nine mainstem (M) and seven tributary (T) sampling locations within three hours per sampling date (Figure 1). These locations were chosen based on landowner permission and physical accessibility with as robust of a sampling regime as possible in order to capture the full rainfall and TSS dynamics of the watershed. Note that while storms that fit the criteria might have been more common during the winter months, several rare ice and snow storms as well as delays in receiving landowner permissions to enter prevented the project from starting until February 2017.

The sampling locations were grouped into mainstem and tributary sampling locations and each sampling location was compared within their own groups (see Figure 1). The mainstem locations were sampled in order to determine the geographical dynamics of TSS concentrations in storm events in the main stretch of McCarthy Creek and to identify specific sections of the mainstem that would likely be in need of targeted restoration work. Additionally, several mainstem sampling locations had a pair of upstream (MU) and downstream (MD) sampling locations for each tributary in order to capture the tributary contributions to TSS concentrations and yields in the mainstem (Figure 1). The TSS concentrations for the tributaries by themselves were compared to one another to identify any tributaries that were more degraded than the rest, as a target for future restoration work. 



Figure 2: Percent Tree Canopy and Percent Impervious Surface from left to right for the McCarthy Creek Watershed according to the 2011 National Land Cover Database (NLCD). The McCarthy Creek stream and boundary data was provided by the West Multnomah Soil \& Water Conservation District.

One sample $250 \mathrm{ml}$ polyethylene bottle was assigned to each sampling event (Clark \& Siu 2008).

The in-stream sampling approach followed the PAWMAP protocol, in which a grab sample bottle was dipped to the closest of the center width of the stream and at a $0.1 \mathrm{~m}-0.2 \mathrm{~m}$ depth from the stream surface (PAWMAP 2014; Peter Abrams, Personal personal communication, 2016; Kreilling and Houser 2016; Mallin et al. 2009). This was done in order to capture the highest velocity of the stream that would have resulted in high TSS mobility (Charters et al. 2015). After every location was sampled during an event, the grab bottles were immediately placed in refrigerated storage until analysis. 


\subsection{Field Measurements - Time Series Sampling}

This part of the study focused on temporal distributions of TSS concentrations during the course of storms and the effects of different cumulative rainfall regimes on hourly TSS concentrations. This required the use of an ISCO 6700 automatic sampler that was programmed to draw one sample for every hour of a candidate storm for a course of 24 hours. The samples were taken immediately to the lab and analyzed in the same manner as the grab sample bottles.

Like the grab-sample collection, this automated sampling was aimed at capturing TSS concentrations in a $250-\mathrm{ml}$ sample during 0.15 in. or greater cumulative rainfall in a 24 -hour period using predictions by the "Weather Underground" forecasting tool. The samples were drawn from the middle width of the stream channel and 0.1 0.2m below the surface of the stream (PAWMAP 2014; Peter Abrams, Personal Communication, 2016; Kreilling and Houser 2016; Coulter et al. 2004).

The autosampler was installed at M7 in order to capture the responsiveness of TSS concentrations at McCarthy Creek to cumulative rainfall at its outlet (Figure 1). Although M8 represents the true outlet, there was enough foot traffic and evidence of transient people camping that M7 was determined to be a safer location. The sampling period for this part of the study only started 3/3/2017 and ended in 4/24/2017 for a total of six storms due to errors with the autosampler and issues with destroyed filters.

\subsection{Laboratory Analysis}

The Laboratory analysis for the field samples followed the Environmental Protection Agency (EPA) Standard Method for TSS (EPA 2540 D) used by PAWMAP (PAWMAP 2014; Peter Abrams, Personal Communication, 2016; EPA 1997). This method was used in order to in order to produce data that is comparable to those used by Portland, OR, area organizations that regulate and analyze water quality. 
Briefly, two 100-mL aliquots of the grab sample were withdrawn after 30 seconds of agitation (Clark \& Siu 2008, APHA 2005). The aliquots were then poured into pre-rinsed and pre-weighed Pall Life Sciences Type A/E glass-fiber filters with a pore size of less than 2 micrometers, vacuum drained, oven dried at $105^{\circ} \mathrm{C}$ for 24 hours, and weighed again to obtain dry weight (Clark \& Siu 2008; APHA 2005). These dry weights were then averaged to determine the mean TSS value per sample. If one of the aliquots resulted in a damaged filter, the non-damaged filter was used as the mean. If both of the filters were damaged for the autosampler measurements, the values were interpolated by using the hourly values before and after the filters in question. If filters were torn throughout a sampling period, they were not included in this study. TSS values were compared to a $43 \mathrm{mg} / \mathrm{L}$ informal threshold that was derived from an average of storm and baseline TSS data used to develop the Watershed Health Index for Johnson Creek \& Willamette Streams by the City of Portland Bureau of Environmental Services (BES) (PAWMAP 2014; ODEQ 2006).

Several steps were taken to prevent sample contamination during storage. After field collection, the samples were immediately capped and refrigerated at a temperature of $4{ }^{\circ} \mathrm{C}$ to prevent algal growth (EPA 1997). All samples used were filtered within a week of data collection to prevent bacterial growth that may artificially increase dry weight values (EPA 1997). All sample bottles were washed with Neutrad detergent and rinsed with deionized water three times to prevent contamination between uses (EPA 1997). 


\subsection{Land Cover Data}

This portion of the study sought to examine relationships between land cover variables and mean TSS concentrations and to identify which, if any, land cover types had a significant effect on mean TSS concentrations.

Each of the land cover areas of McCarthy Creek were analyzed using the United States Geological Service's Streamstats tool to delineate sub-drainage basins by using the tributary and mainstem sampling locations as outlets (Figures 1-3; USGS-Streamstats 2017). Although the Tributary basins were divided with no overlap between them, the mainstem sampling locations by their nature overlapped significantly, leading to significant spatial autocorrelation that needed to be addressed. To aid in reducing autocorrelation, the overlapping sections for each drainage basin were eliminated, leaving only basin areas that were exclusive to each. Only the sub-basins derived from the upstream mainstem sampling locations were used, due to the similarities in land cover between paired upstream and downstream sampling locations and for the sake of consistency. This would minimize spatial autocorrelation, but not completely eliminate it.

To calculate TSS yields from TSS concentrations, estimates of discharge were from the sub-basin drainage areas and 5, 10, 25 peak year flows from each delineated sub-basin made using StreamStats, resulting in mean 5, 10, 25 peak year flow TSS yields for each sub-basin. TSS yields were included in this study because TSS concentrations may be of limited use in determining TSS sources if there are significant differences in peak flow in each sub-basin: high concentrations but low flows may have less TSS loading compared to low concentrations but extremely high flow. This approximation of discharge was the only storm flow data available at the sub-basin scale, given that actual flow measurements could not be made within the scope of this project and a USGS stream gage was not present. 

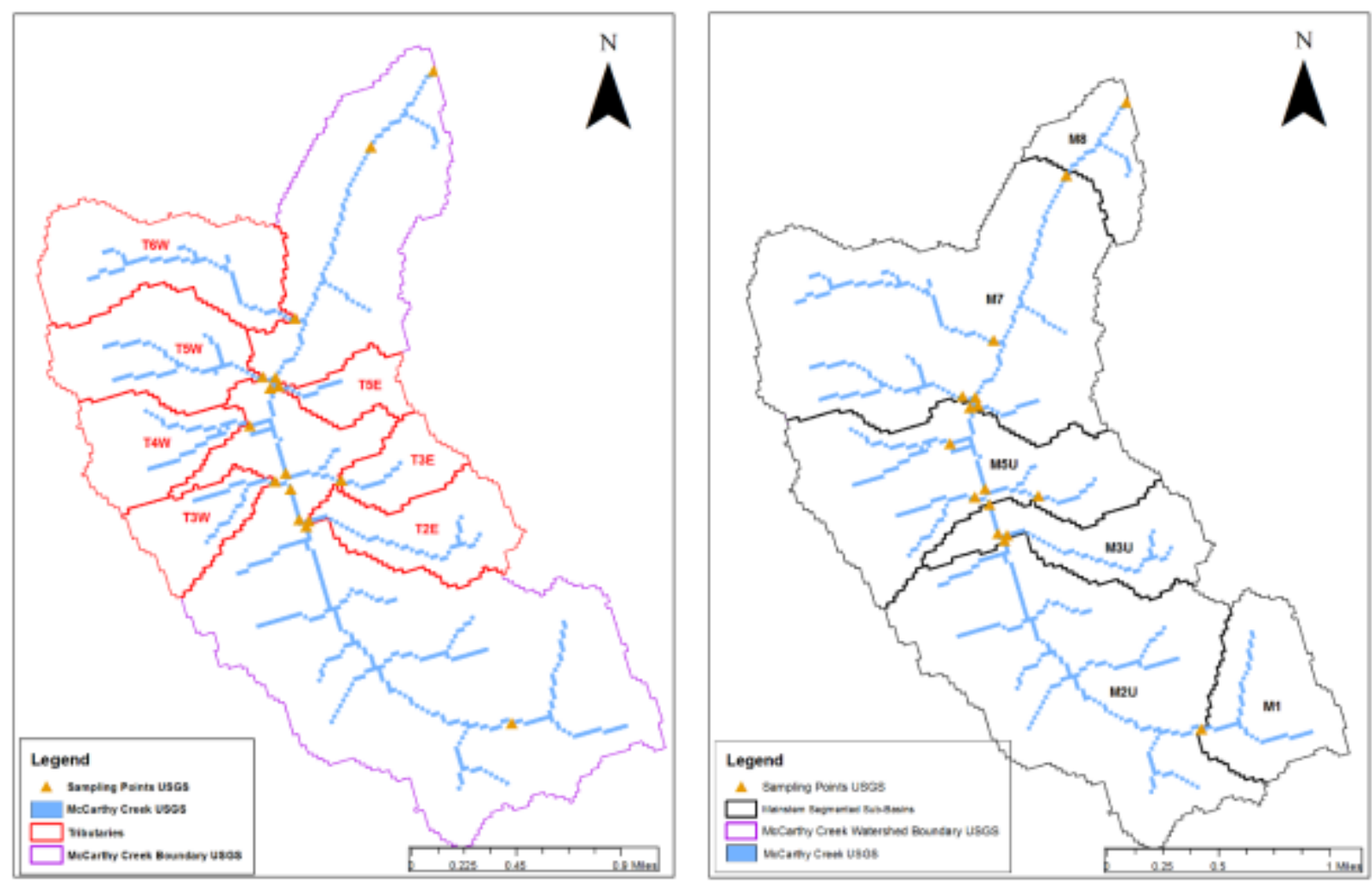

Figure 3: Tributary and the segmented mainstem boundaries as outlined by the USGS-StreamStats tool for the Tributary sampling locations of the (raster) McCarthy Creek Watershed (USGS-Streamstats 2017). The McCarthy Creek stream and boundary data was provided by the West Multnomah Soil \& Water Conservation District.

The land cover values chosen for this study were mean percentage tree cover $(\mathrm{C})$, mean percentage impervious surface (I), and mean basin slope (S) (Figure 2). C represented the average percentage number of tree cover per 3x3 m pixel and I represented average percentage impervious surface area per (Including roads, driveways, and roofs) $3 \times 3$ pixel; both were derived and interpolated from Landsat 5 and 7 imagery (Homer et al. 2004. These were chosen due to their documented effects that include increasing interception, storm-water runoff, and erosion (Mallin et al. 2009; Singh and Chang 2014; Borris et al. 2014). I and C were obtained from the "USFS Tree Canopy Cartographic" and "Percent Development Imperviousness" sub-datasets of the National Land Cover Database 2011, while S was calculated from the USGS Streamstats tool alongside the 5, 10, 25 year peak flows (Table 1; USGSStreamstats 2017; USGS-NLCD 2011). These datasets best represented total tree canopy while masking obviously non-tree areas and isolating total impervious surface area (USGS-NLCD 2011). 
Table 1: Data sources used for the course of this study.

\begin{tabular}{|c|c|c|}
\hline Data & Source & Address \\
\hline Hourly Rainfall (inches) & City of Portland HYDRA Rainfall Network (USGS) & https://or.water.usgs.gov/precip/sauvies_island.rain \\
\hline Peak Discharge (cfs) & USGS Streamstats & https://streamstatsags.cr.usgs.gov/ss_bp/ \\
\hline $\begin{array}{c}\text { Percentage Tree Canopy } \\
(\%)\end{array}$ & $\begin{array}{c}\text { National Land Cover Database 2011 (USGS): USFS } \\
\text { Tree Canopy cartographic (30m) }\end{array}$ & https://www.mrlc.gov/nlcd11_data.php \\
\hline $\begin{array}{c}\text { Percentage Impervious } \\
\text { Surface Area (\%) }\end{array}$ & $\begin{array}{r}\text { National Land Cover Database 2011 (USGS): Percent } \\
\text { Developed Imperviousness (30m) }\end{array}$ & https://www.mrlc.gov/nlcd11_data.php \\
\hline Mean Basin Slope (S) & USGS Streamstats & https://streamstatsags.cr.usgs.gov/ss_bp/ \\
\hline Project Boundaries $(\mathrm{m})$ & West Multnomah Soil \& Water Conservation District & \\
\hline
\end{tabular}

\subsection{Statistical Analysis}

All nonspatial statistical analysis was conducted with the software package "R-Studio" (RStudio Team 2016). All spatial statistical analysis was conducted with GEODA (Anselin et al. 2006).

\subsubsection{Spatially Extensive TSS Concentration \& Peak Flow Yield Sampling}

The spatially extensive portion of the study strove to determine if there were statistically significant differences in TSS concentrations and mean peak flow yields among mainstem sampling locations and among tributary sampling locations. The latter were calculated using the drainage basin areas and peak 5, 10, 25 year flows combined with the TSS concentrations found at the tributary and segmented mainstem sampling points (Figures 2-3). Mean TSS concentrations and mean cumulative rainfall periods were used due to the unchanging nature of the land cover types during the sampling period, and were calculated from the means of the grab sample locations and cumulative rainfall periods.

Two sets of ANOVA were performed on TSS concentrations and mean peak flow yields within the mainstem and tributary groups to determine if statistically significant differences actually existed. If they did, a Tukey HSD test was performed to determine the magnitude of difference between each 
location. Those that were statistically higher than the others were determined to be the highest priority for environmental restoration by the WMSWCD.

Due to the nature of the data, normality and independence of observations/autocorrelation would need to be tested in order to fulfill assumptions of the ANOVA and all of the statistical tests. The Shapiro-Wilks test was used to test for normality: If any results indicating a p-value $<0.05$, then the data was log-transformed and a Shapiro-Wilks test was performed again. Spatial autocorrelation of both TSS concentrations and mean peak flow yields were not a problem with the tributaries due to being spatially independent. However, mainstem sampling locations are by nature autocorrelated and would likely produce an artificially low p-value. The ANOVA was still performed to determine the magnitude of differences with the effects of autocorrelation in mind.

The upstream-downstream mainstem locations were statistically compared to one another using ttests in order to minimize the influence of other mainstem sampling locations. This was due to the likely issues with spatial autocorrelation of the mainstem sampling data. Additionally, the magnitude of the possible statistically significant differences between upstream-downstream mainstem sampling locations can also determine if a tributary had a dilution or contributing effect on TSS concentrations or yields.

\subsubsection{Regression Analysis of TSS Concentrations \& Rainfall Characteristics}

All of the TSS concentration data for the mainstem and tributary sampling locations were analyzed using in linear regression to determine the effects of RH, RI, and RD on TSS concentrations (Mallin et al. 2009; Zhang et al. 2015; Murphy et al. 2015a; Goore Bi et al. 2015). RH, RI, and RD were derived from the nearest rainfall tipping bucket of the Portland HYDRA network run by the USGS (HYDRA 2017). The Sauvie Island location was determined to be the closest to the study area and was chosen due to the lack of available USGS monitoring stations closer to the site and the robustness of the HYDRA data (Table 1). Each rainfall characteristic was used to produce regression models with each RH 
scenario as the predictor variable for TSS concentrations (USGS 2017 and Mallin et al. 2009). The regression model with the lowest p-value was determined to be the most statistically significant, while the highest Adjusted $\mathrm{R}^{2}$ values determined the strongest relationship between a rainfall characteristic and TSS concentrations.

\subsubsection{Regression Analysis of Time Series Trends in TSS Concentrations}

Temporal trend data by nature is highly autocorrelated, thus autocorrelation of the automated TSS sample data that was collected over the course of storm events needed to be at least minimized to prevent artificially high adjusted $\mathrm{R}^{2}$ and lower p-values. To reduce the effects of temporal autocorrelation, a generalized least squares (GLS) model for TSS concentrations was created for each rainfall scenario. Each of these models were analyzed for statistical significance $(\mathrm{p}<0.05)$, and those that were statistically significant were ranked using Akaike information criterion (AIC) scores in which the lowest AIC represents the best fit model. The data was tested for normality through the Shapiro-Wilks test; if the data failed the normality test, results were first log-transformed. A box-cox transformation was performed if the log transformation failed Shapiro-Wilks as well.

\subsubsection{Spatial Analysis of TSS Concentrations as a Function of Land Cover}

The land cover variables I, C, S, and cumulative rainfall for the tributaries and segmented mainstem areas underwent a robust spatial analysis to predict TSS concentrations as well as mean peak flow TSS yields. This included Ordinary Least Squares (OLS) and resultant Spatial Error or Lag Regression equations for five cumulative rainfall scenarios and all three peak flow TSS yields. These were created with the intent of eliminating the effects of spatial autocorrelation, error, and lag for all of the variables to determine the true statistically significant relationships between any of them. 
Initially, multiple OLS equations were created using original or transformed TSS concentration and peak flow TSS yields data for all cumulative rainfall scenarios and all peak flow scenarios for both tributaries and segmented mainstem drainage sub-basins. The diagnostics from the OLS models would determine if any spatial lag or spatial errors models were needed. These diagnostics included an overall $p$-value for the model to determine if the OLS equation was significant $(p<0.05)$, the multicollinearity test ( significance $=>30)$, the Jarque-Bera test for normality ( significance $=p<0.05)$, the Breusch-Pagan test for heteroscedasticity ( significance $=\mathrm{p}<0.05$ ), Moran's I test for autocorrelation ( significance $=\mathrm{I}>0.5$ or $\left.\mathrm{I}<^{\prime}-0.5^{\prime}\right)$. Any failures of these diagnostics would require additional TSS concentration and peak flow TSS yield transformations to achieve normality or heteroscedasticity, as well as several variable inflation factor (VIF) stepwise runs to eliminate multicollinear variables and achieve a VIF score greater than 5 . Then an OLS with the transformed data and the remaining variables would be run again and undergo the same diagnostics.

If both the OLS and Moran's I proved to be significant ( $\mathrm{p}<0.05$; Moran's $\mathrm{I}>0.5$ or $\mathrm{I}<{ }^{\prime}-0.5^{\prime}$ ), then the spatial lag and spatial error diagnostics will be analyzed. If one was significant $(\mathrm{p}<0.05)$ over the other, then the correct spatial model was used containing the remaining variables. In doing so, spatial autocorrelation should effectively be eliminated through the creation of a spatial lag or spatial error variable. Then the resultant spatial regression models were compared to one another using AIC scores to determine the best fit. This resulted in a statistically robust spatial regression model that best reflected the relationship between TSS concentrations, TSS yields, and land cover variables.

\section{Results}

\subsection{Spatially Extensive TSS Sampling during Storm Events}

Sampling took place between the dates of $2 / 15 / 17$ to $5 / 11 / 17$, with 8 observed storms exceeding 0.15 inches within 24 hours, with one grab sample collected at each location during each storm (Figure 4). Eight samples were recorded for every location for a total of 128 samples throughout the course of the 
study ( $\mathrm{n}=16$ locations, $\mathrm{n}=128$ total). All of the samples during a storm event were taken within 2 hours of one another and were processed within a week of collection.

\section{Spatially Extensive Sampling Date to Daily Rainfall (in.)}

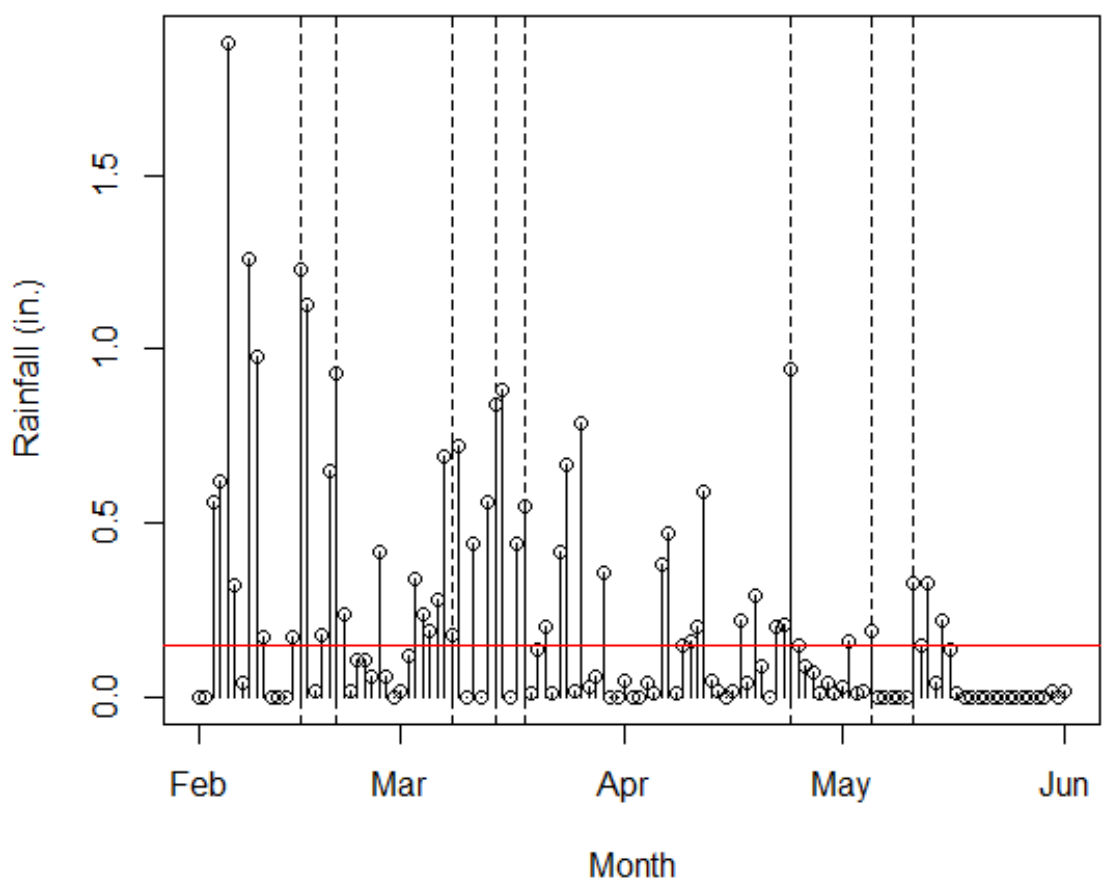

Figure 4: Sampling dates and 24-hour accumulated rainfall between February to June 2017. The dashed lines represent sampling dates while the red line represents 0.15 inches of cumulative 24 hour rainfall.

The combined mean for the entire watershed was $79.82 \mathrm{mg} / \mathrm{L}$, well above the $43 \mathrm{mg} / \mathrm{L}$ informal threshold (Table 2). All observed locations surpassed the $43 \mathrm{mg} / \mathrm{L}$ informal threshold in means and in medians other than M3D (Table 2). The range and variance were extremely large, and the CV revealed substantial variation for the entire watershed at 147.7 (Table 2). Between the two sampling groups, the mainstem locations had higher TSS concentrations than the tributary sampling locations (Table 2). 
Table 2: Summary statistics of TSS (mg/L) concentrations of each Tributary and Mainstem (Segmented) sampling point of McCarthy Creek, listed in upstream to downstream order.

\begin{tabular}{cccccc} 
Location & Mean & Median & Range & $\begin{array}{c}\text { Standard } \\
\text { Deviation }\end{array}$ & CV \\
\hline M1 & 104.7 & 71 & 414 & 134.3 & 128.3 \\
M2U & 77.81 & 38 & 376.5 & 125.2 & 160.0 \\
M2D & 81.63 & 43.25 & 343.5 & 115.4 & 141.4 \\
M3U & 86.25 & 59.75 & 311.5 & 103.7 & 120.3 \\
M3D & 104.2 & 37.25 & 461 & 177.3 & 170.3 \\
M5U & 95.75 & 49 & 445.5 & 147.4 & 154.0 \\
M5D & 118.4 & 64.75 & 532.5 & 174.9 & 147.8 \\
M7 & 174.1 & 117 & 831.5 & 272.9 & 156.7 \\
M8 & 194.9 & 117.8 & 884.5 & 290.6 & 149.1 \\
\hline All Mainstem & $\mathbf{1 1 5 . 6}$ & $\mathbf{5 6}$ & $\mathbf{8 8 6 . 5}$ & $\mathbf{1 7 6 . 6}$ & $\mathbf{1 5 2 . 7}$ \\
\hline T2E & 89.38 & 76.75 & 266.5 & 93.21 & 72.65 \\
T3E & 91.31 & 75.5 & 316 & 103.7 & 64.43 \\
T3W & 72.88 & 22.75 & 322 & 110.6 & 78.19 \\
T4W & 73.19 & 48 & 236 & 79.88 & 66.42 \\
T5E & 71.75 & 40 & 191.5 & 76.48 & 44.93 \\
T5W & 104.3 & 65.75 & 474 & 156.2 & 101.45 \\
T6W & 55.94 & 37.75 & 192.5 & 64.49 & 43.65 \\
\hline All & $\mathbf{7 9 . 8 2}$ & $\mathbf{5 1 . 7 5}$ & $\mathbf{4 7 7 . 5}$ & $\mathbf{9 7 . 1 9}$ & $\mathbf{1 2 1 . 8}$ \\
\hline Tributaries & & & & $\mathbf{1 4 7 . 7}$ \\
\hline All Locations & $\mathbf{9 9 . 7 1}$ & $\mathbf{5 4 . 2 5}$ & $\mathbf{8 8 6 . 5}$ & $\mathbf{1 4 7 . 2 5}$ & \\
\hline
\end{tabular}

For the entire watershed, the highest mean TSS concentrations were found at the two furthest downstream locations (M8 and M7; Table 2); these values were at least $65.5 \%$ and $47.1 \%$ higher than the mean of all other sampling locations respectively. Almost all of the mainstem locations had higher mean values than the tributary sampling locations (Table 2). However, one tributary (T5W) had higher mean TSS concentrations than the four lowest mainstem sampling locations (Table 2). While there was a general pattern of increasing mean TSS concentrations from upstream to downstream, the overlapping standard errors for all sampling points suggest no significant differences between sampling locations (Figure 5). 


\section{Mainstem Mean TSS (mg/l) values by Distance}

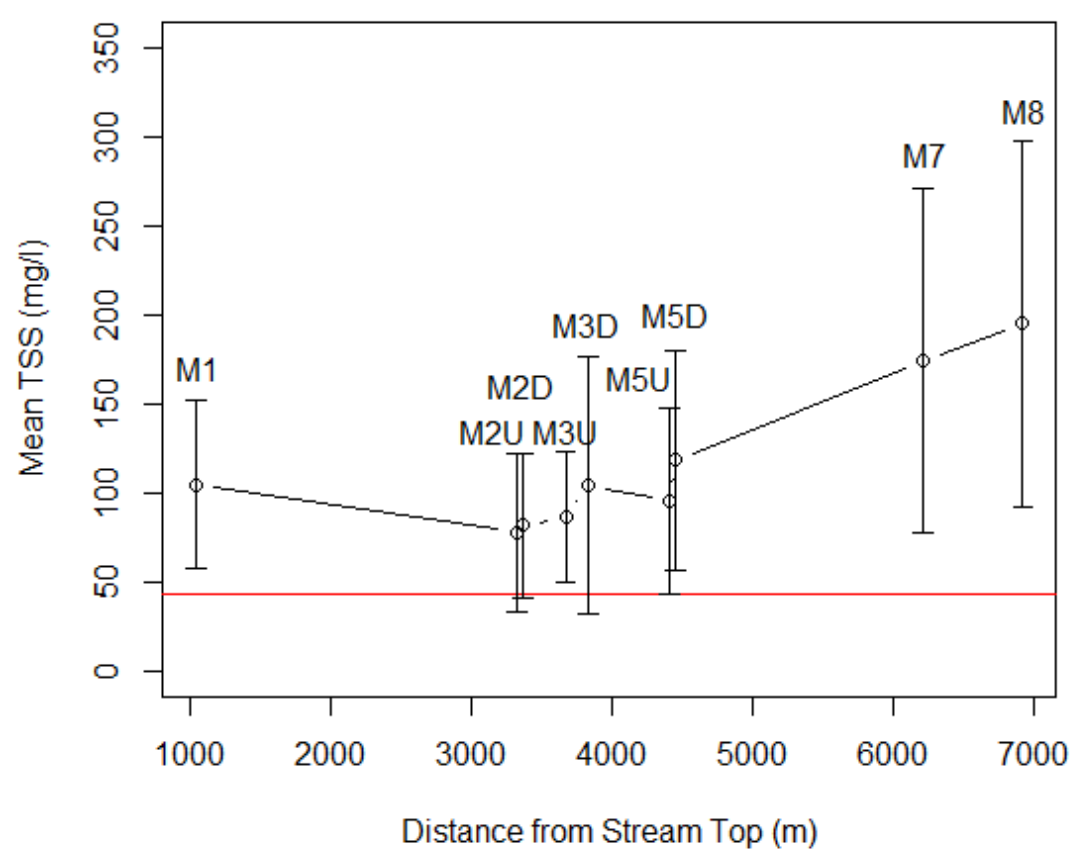

Figure 5: Mean TSS values of sampling points and associated Standard Error by geographic distance, from top of the watershed to the outlet for the mainstem sampling locations ( $\mathrm{n}=8$ for each location). The red line represents the $43 \mathrm{mg} / \mathrm{L}$ watershed informal threshold informed by BES and ODEQ. Note that mean values for each sampling point are above the informal threshold during a storm event. A total of 8 storm events were sampled at each location $(n=72)$.

The tributary sampling locations did not have a similar upstream to downstream pattern in the geographical distribution of mean TSS concentrations. All of the tributary TSS means were higher than the $43 \mathrm{mg} / \mathrm{L}$ TSS concentration informal threshold (Table 2; Figure 6). Again, the overlapping standard errors show considerable within-site variability and suggest no significant differences among the tributary sampling locations (Figure 6). 


\section{Tributary Mean TSS (mg/l) values by Distance}

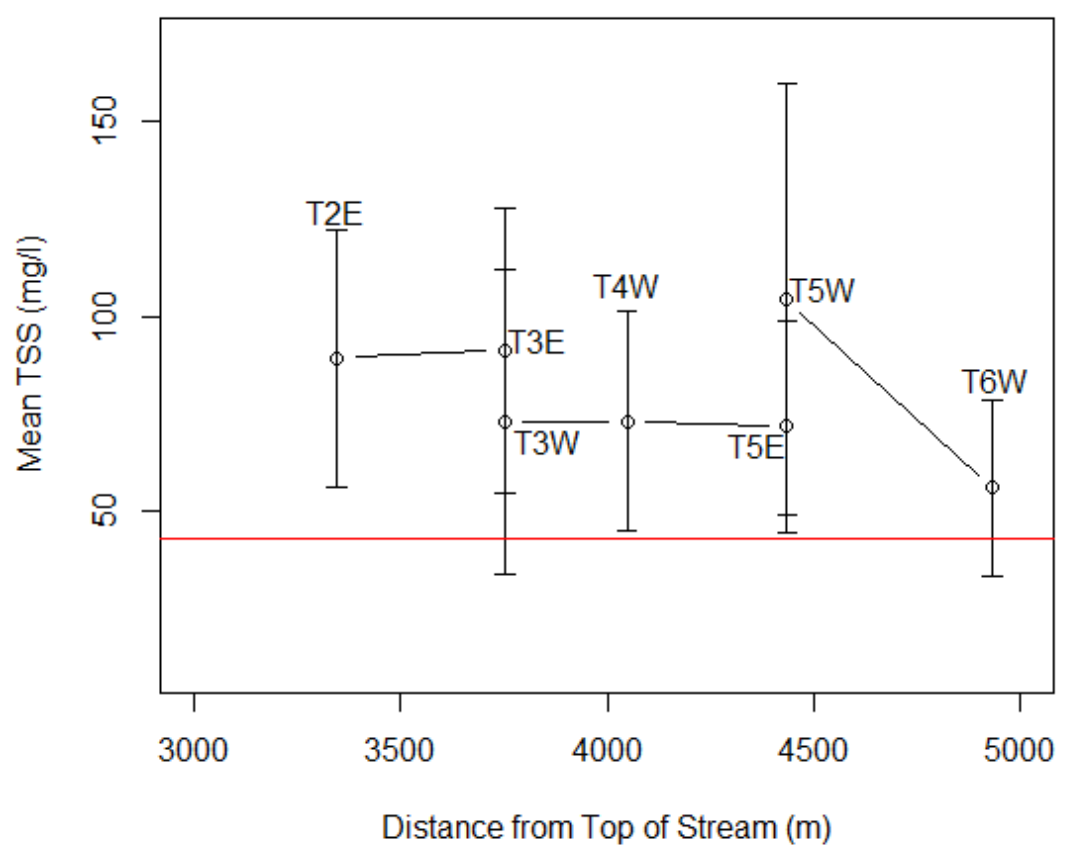

Figure 6: Mean TSS and mean LogTSS values of sampling points by geographic distance, from top of the watershed to the outlet for the Tributary sampling locations ( $\mathrm{n}=8$ for each location). The red line represents the (log transformed) $43 \mathrm{mg} / \mathrm{L}$ watershed informal threshold informed by BES and ODEQ. Note that the values for each sampling point are above the informal threshold during a storm event.

\section{$\underline{\text { 3.1.2 Spatially Extensive ANOVA and T-test results }}$}

Despite the subtle longitudinal pattern of increasing TSS concentrations from upstream to downstream, no statistical differences were found in TSS between mainstem sampling locations using ANOVA of log-transformed TSS concentrations (LogTSS) during storm events $(\mathrm{F}=0.2311 ; \mathrm{p}$-value $=$ 0.9468). LogTSS values were used due to being normally distributed, as they had passed the ShapiroWilks test $(\mathrm{W}=0.96919, \mathrm{p}$-value $=0.2356)$.

To detect any influence of tributaries on mainstem TSS concentrations, I examined differences between paired mainstem locations upstream and downstream of tributary junctions. Although every downstream sampling site had higher TSS concentrations compared to its upstream counterpart, no pairs of mainstem sampling locations differed significantly (Table 2 and Figure 5: p-value > 0.05). As with the 
ANOVA, autocorrelation and non-parametric distribution did not affect the outcome, as the results were not statistically significant. The smallest difference in mean TSS concentrations between upstream and downstream points was found for the first upstream pair (between M2U and M2D), with differences increasing in magnitude moving further downstream, except for a relatively small decrease at the last downstream pair (M7-M8) (Table 2 and Figure 5).

\footnotetext{
Table 2: T-Test results of mainstem upstream and downstream sampling points for TSS. Note that all models have a $\mathbf{P}$-value $>0.05$ $(n=72)$, indicating no significant difference between the paired mainstem sampling locations. The highest difference in mean TSS between upstream and downstream paired sampling points is between M5U versus M5D.
}

\begin{tabular}{ccc}
$\begin{array}{c}\text { Sampling } \\
\text { Locations } \\
\text { Compared }\end{array}$ & $\begin{array}{c}\text { Difference in } \\
\text { Mean TSS } \\
(\mathbf{m g} / \mathbf{L})\end{array}$ & $\begin{array}{c}\text { p-value } \\
\text { (LogTSS) }\end{array}$ \\
\hline M2U-M2D & 3.81 & 0.8763 \\
M3U-M3D & 17.92 & 0.4956 \\
M5U-M5D & 22.63 & 0.6999 \\
M7-M8 & 20.81 & 0.08471
\end{tabular}

The tributaries displayed similar statistical results as the mainstem sampling locations: there were no statistically significant differences in mean TSS concentrations for all tributaries of McCarthy Creek. This was indicated by the $\mathrm{p}$-value greater than the 0.05 cutoff from the ANOVA analysis $(\mathrm{F}=0.1343$; $\mathrm{p}$ value $=0.9912)$

\subsection{Spatially Extensive Sampling Estimated TSS Yields During Storm Events}

TSS yields (tons/sqmi/yr) were calculated from using TSS (mg/L) concentrations that were converted to tons/cf, and from 5, 10, 25-year peak flows (cfs) estimated in Streamstats and their proper unit conversion to produce TSS loads (tons/yr). The loads were divided by the total area of each drainage basin in square miles for each sampling point derived from Streamstats (USGS 2017). 


\subsubsection{Spatially Extensive Estimated TSS Yields ANOVA Results}

Table 3: ANOVA results of TSS Yields (Tons/sqmi/yr) and Log TSS Yields under 5, 10, and 25-year peak flow regimes for the mainstem sampling locations. Note that none of the $p$-values are $<\mathbf{0 . 0 5}$, indicating no significant differences for TSS yields for any of the mainstem sampling locations $(n=72)$.

\begin{tabular}{ccc} 
Model & F & P-value \\
\hline TSS Yields from 5 Year Peak Flow & 0.5087 & 0.768 \\
TSS Yields from 10 Year Peak Flow & 0.4479 & 0.8123 \\
TSS Yields from 25 Year Peak Flow & 0.4492 & 0.8114 \\
Log TSS Yields from 5 Year Peak Flow & 0.3683 & 0.8674 \\
Log TSS Yields from 10 Year Peak Flow & 0.332 & 0.8907 \\
Log TSS Yields from 25 Year Peak Flow & 0.3357 & 0.8885
\end{tabular}

The entire watershed had statistically similar calculated discharge values and TSS yields at each sampling point; neither the TSS yields (tons/sq mi/yr) for the mainstem nor the tributary sampling points were significantly different from one another in any of the scenarios (Tables 3 and 4: p-values $>0.05$ ). Although autocorrelation and non-normal distributions were present in the mainstem locations, the impacts of either on the yield values would only serve to diminish p-scores; the fact that the calculated pvalues were greater than 0.05 indicates that Type I errors were absent (Table 4).

Table 4: ANOVA results of TSS Yields (Tons/sqmi/yr) and Log TSS Yields under 5, 10, and 25-year peak flow regimes for the Tributary sampling locations. Note that none of the $p$-values are $<0.05$, indicating no significant differences for TSS yields for any of the mainstem sampling locations $(\mathbf{n}=56)$.

\begin{tabular}{ccc} 
Model & F & P-value \\
\hline TSS Yields from 5 Year Peak Flow & 0.7867 & 0.5846 \\
TSS Yields from 10 Year Peak Flow & 0.2205 & 0.9684 \\
TSS Yields from 25 Year Peak Flow & 0.2202 & 0.9685 \\
Log TSS Yields from 5 Year Peak Flow & 0.46 & 0.8344 \\
Log TSS Yields from 10 Year Peak Flow & 0.1465 & 0.9889 \\
Log TSS Yields from 25 Year Peak Flow & 0.1465 & 0.9889
\end{tabular}



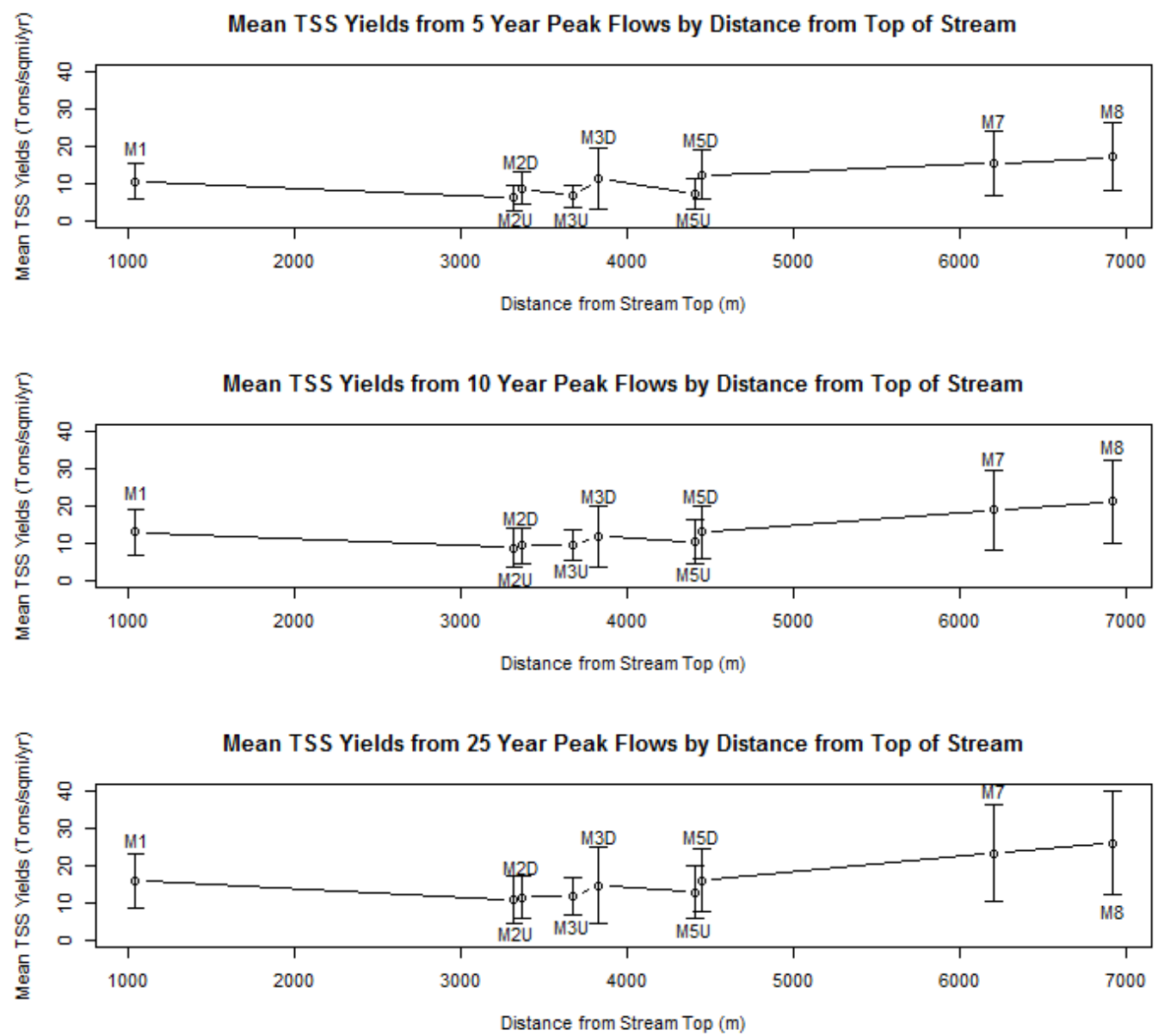

Figure 7: Mean TSS Yields (Tons/sqmi/year) of mainstem sampling points by geographic distance from top of the watershed to the outlet for 5, 10, and 15 year peak flows $(n=72)$. Note that all downstream sampling points have (non-statistically significant) higher mean yields than their upstream counterparts for all peak flow scenarios.

The mean mainstem TSS yields for each sampling produced the same geographic pattern with the mean mainstem TSS concentrations (Figures 5 and 7). In both instances, there was a general trend of mean TSS yields increasing from the headwaters to the outlet (Figures 5 and 7). However, the ANOVA results indicate that these differences are not statistically significant (Tables 3 and 4).

No significant differences were found among the tributary sampling locations for the 5,10 , or 25 peak year flow regimes for LogTSS Yields (Table 5; p>0.05). Although the TSS yields and LogTSS yield from 5 Year peak flow did not have normal distribution, autocorrelation was not an issue due to the independence of each tributary from one another. This resulted in a lack of significant differences among 
the tributary sampling locations and there weren't any consistent patterns in magnitude and geographical distribution in mean TSS Yields and LogTSS yields.
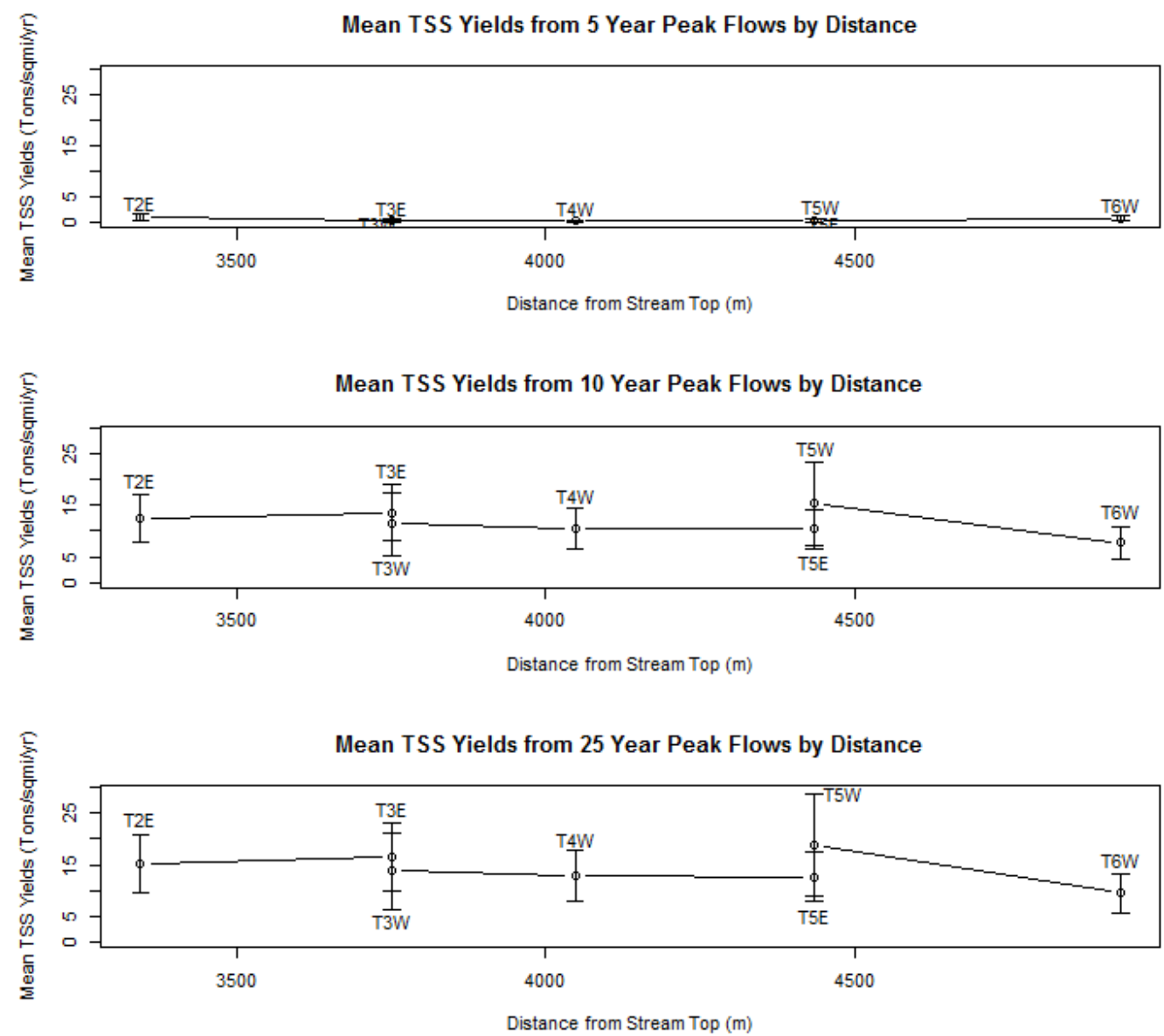

Figure 8: Mean TSS Yields (Tons/sqmi/year) of tributary sampling points by geographic distance from top of the watershed to the outlet for 5, 10, and 15 year peak flows ( $n=8$ for each sampling location). Note that this data was not normally distributed.

\subsection{Linear Regression of Rainfall Characteristics and Spatially Extensive Data during Storm Events}

While no spatial differences were found in TSS concentrations for either mainstem or tributary

data, RH and RI were strong predictors of TSS concentrations across the watershed due to p-values $<0.05$ (Figures 9 and 10).

Regression models for the mainstem sampling locations produced $\mathrm{p}$-values $<0.05$ and adjusted $\mathrm{R}^{2}$ from 0.08 to 0.56 (Figure 9). Overall, the $\mathrm{RH}$ model displayed the strongest relationship as it had the 
lowest AIC score at 217.9, while the RD model had the highest AIC score of 270.0 (Figure 9). However, autocorrelation for the LogTSS values likely inflated the $\mathrm{R}^{2}$ value and an artificially low $\mathrm{p}$-value due to being sampling points along the same stream (Figure 9).
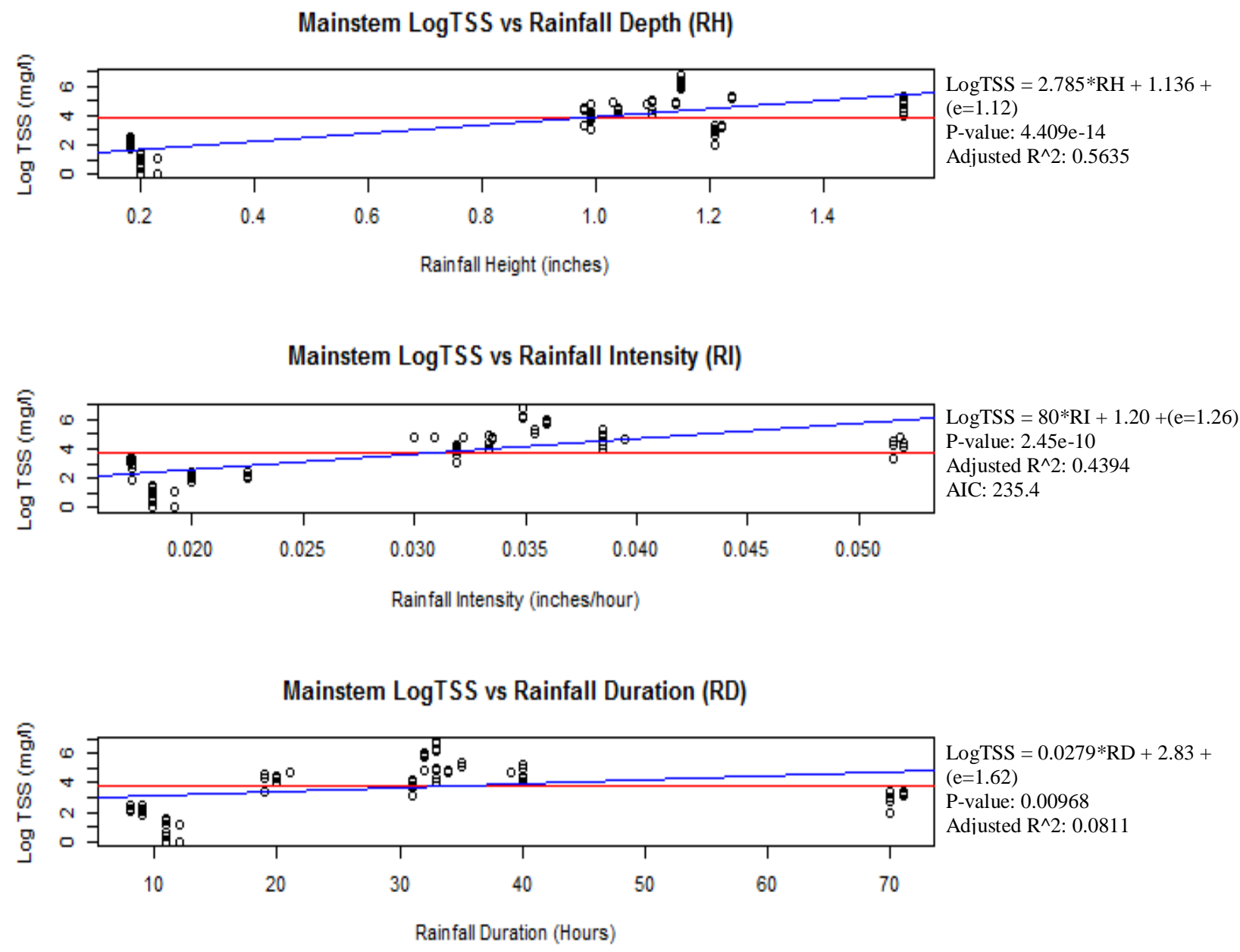

Figure 9: Linear Regression plots of LogTSS as a function of RH, RI, and RD for the mainstem sampling locations. All p-values were $<0.05$, indicating a significant relationship between all prior rainfall scenarios and $\operatorname{LogTSS}\left(\mathrm{n}=72\right.$ ). Adjusted $\mathbf{R}^{2}$ was $<0.5$ for the $\mathbf{R I}$ and RD models. The lowest AIC score was found for the RH model. The blue line represents the Linear Regression line, while the red line represents log (43), or the log transformed TSS informal threshold informed by BES and ODEQ.

There were significant statistical relationships for all tributary linear regression models of LogTSS and RH, RI but not RD. While RH and RI had p-values < 0.05 , RD had a p-value >0.05; this indicated a lack of statistical relationship between LogTSS and RD (Figure 10). The model with the lowest AIC score (160) was the RI model and was therefore this was best fit model (Figure 10). Since 
these tributary measurements were spatially independent, the problems with autocorrelation seen with mainstem results do not apply, rendering these relationships more robust.

Tributary LogTSS vs Rainfall Depth (RH)

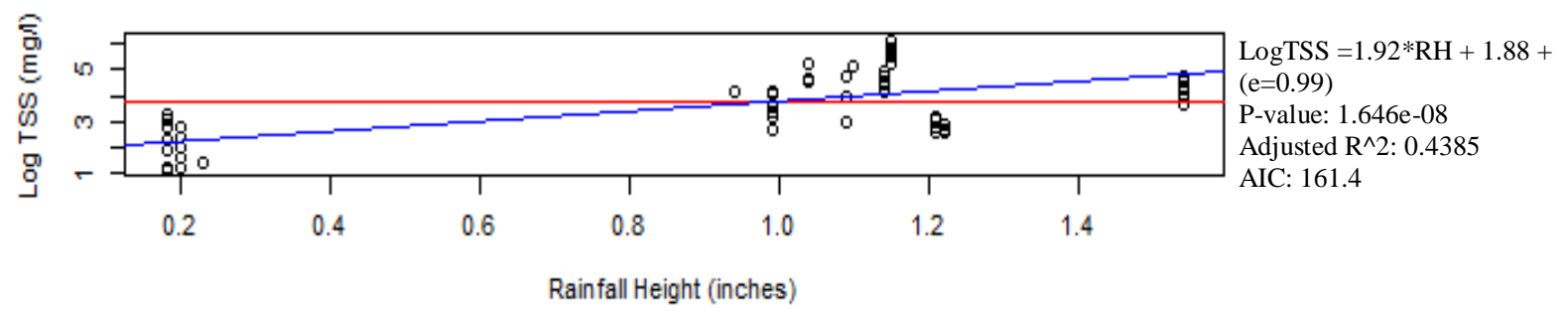

Tributary LogTSS vs Rainfall Intensity (RI)

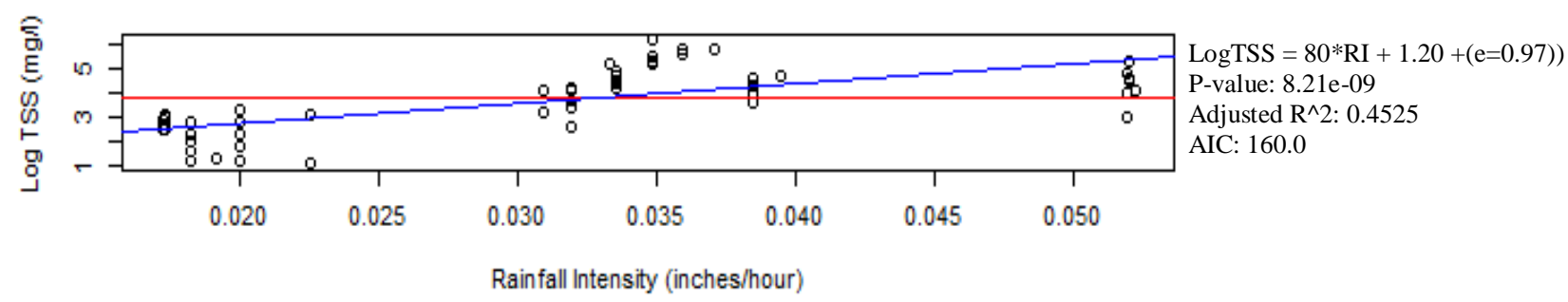

Tributary LogTSS vs Rainfall Duration (RD)

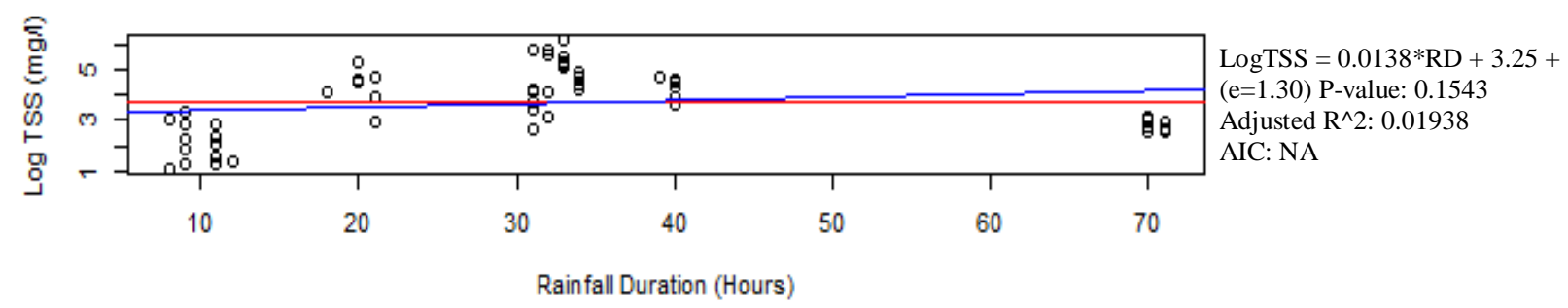

Figure 10: Linear Regression plots of LogTSS as a function of RH, RI, and RD for the tributary sampling locations. All p-values were $<0.05$, indicating a significant relationship between all prior rainfall scenarios and LogTSS (n=72). Adjusted $\mathbf{R}^{2}$ was $<0.5$ for all models. The lowest AIC score was found in the RI model. The blue line represents the Linear Regression line, while the red line represents log (43), or the log transformed TSS informal threshold informed by BES and ODEQ.

\subsection{Time Series Trend Summary}

Sampling took place between the dates of 3/3/17 to 4/27/17, with over 6 observed storms exceeding 0.15 inches within 24 hours (See Figure 11). In total, 19 out of 160 measurements exceeded the $43 \mathrm{mg} / \mathrm{L}$ informal threshold. Higher TSS values were generally seen with increasing rainfall (Figure 
12). In general, the autosampler caught the beginning of each storm and was able to capture the rising limb of the hydrograph but did not sample the entirety of the storm (Figure 12).

Time-series Sampling Date to Daily Rainfall (in.)

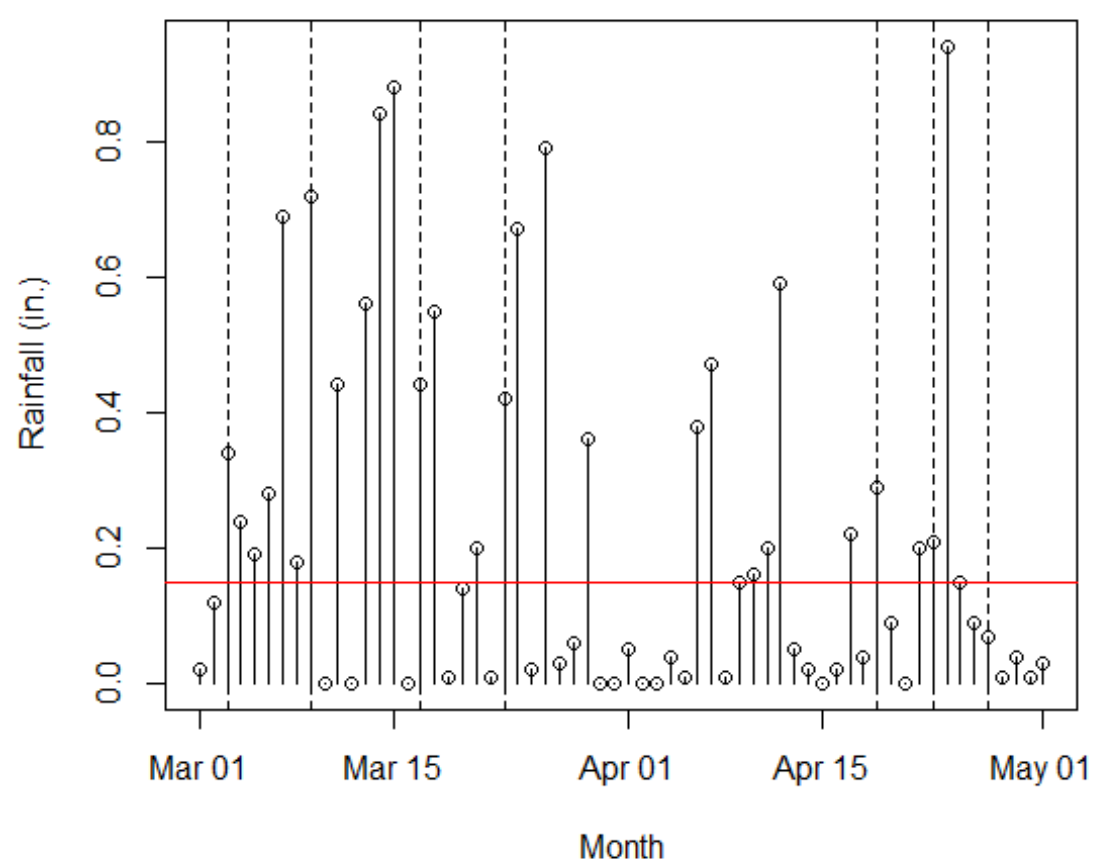

Figure 11: Sampling dates and 24-hour accumulated rainfall between March to May for the Time-Series portion of the study. The dashed lines represent sampling dates while the red line represents 0.15 inches of cumulative 24 hour rainfall.

Visually speaking, there was a slightly greater TSS response for the last three out of the total of six storms with accumulated rainfall greater than 0.15 inches within a 24-hour period sampled (Figures 11, Tables A1-A6). This is likely due to the higher average cumulative rainfall between the two periods (Figure 11 and 12). However, storm structure differed greatly on an hourly basis; this makes trend determination and comparison between storms effectively impossible (Figure 12). Only very generalized trends over the sampling period can be described. 


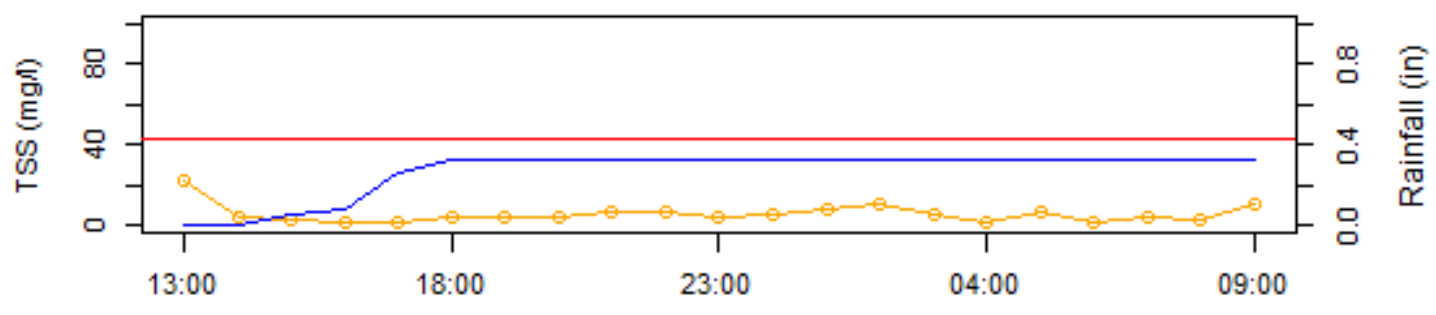

Time During 3/3/17-3/4/17
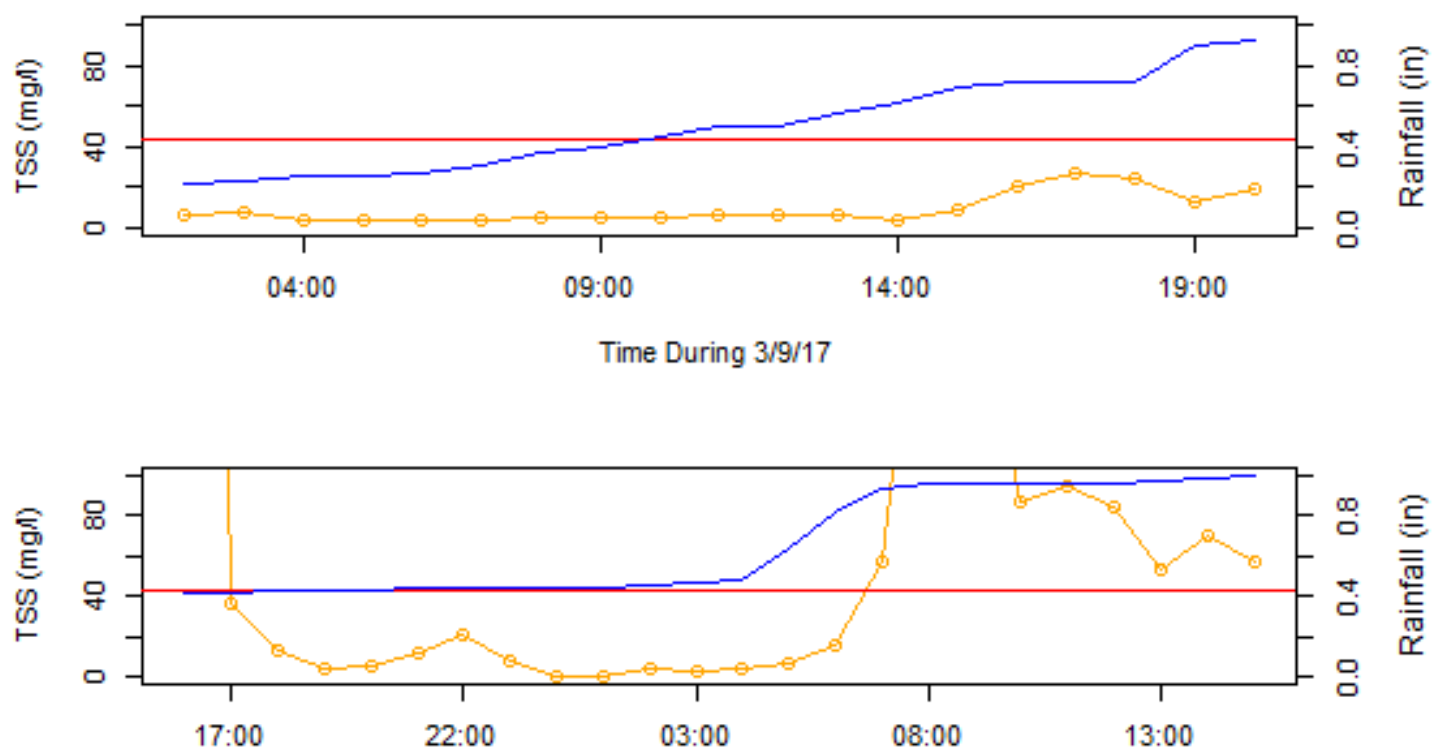

Time During 3/17/17-3/18/17 


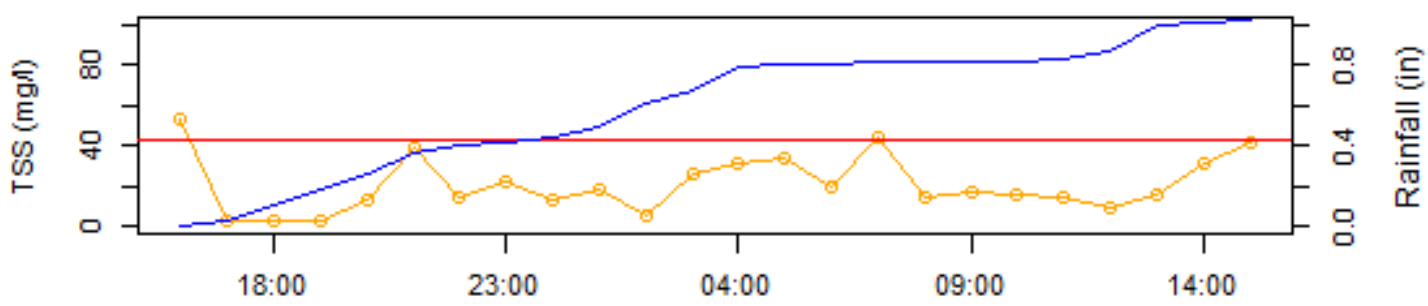

Time During 3/23/17-3/24/17

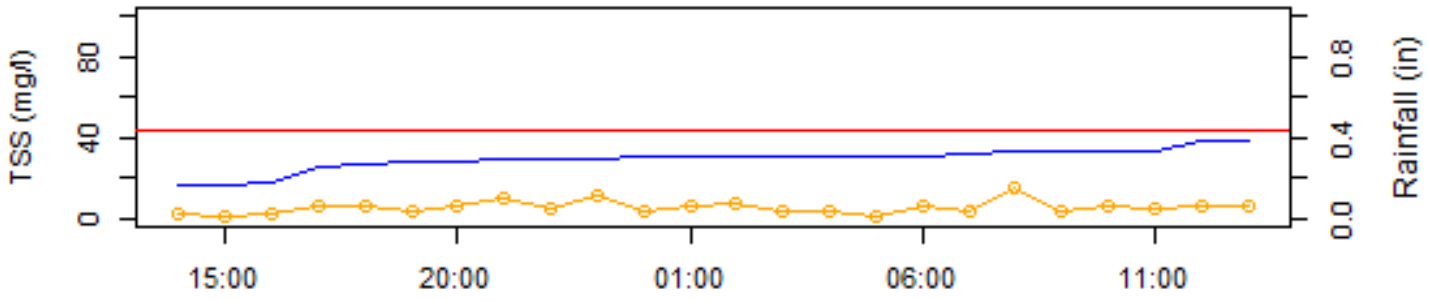

Time During 4/19/17-4/20/17



Time During 4/23/17-4/24/17

Figure 12: 3-axis plot of TSS (mg/L), RH, and time for different sampling dates from the autosampler data. The blue line represents 24hour cumulative rainfall at a given time, while the red line represents the $43 \mathrm{mg} / \mathrm{L}$ TSS informal threshold informed by BES and ODEQ. TSS concentrations were used instead of the boxcox transformation in order to display the temporal, TSS, and rainfall relationships more clearly. From earlier storms to the last, the total $\mathrm{RH}$ at the end of each sampling period were 0.33 in., 0.71 in., 0.58 in. $($ Average $=$ $(0.54)) ; 1.02$ in., 0.28 in., and 1.05 in. (Average = (0.78));

\subsubsection{Time-series GLS Model Results}

When the GLS models were applied to find the relationships between $\operatorname{TSS}^{(-0.1)}$ and each rainfall characteristic while eliminating autocorrelation, the RH model proved to be the best fit model (Figure 13). The RH model had the lowest AIC score out of all of the models and was the only one with a significant p-value, (Figure 13). Therefore, RH was the only statistically significant predictor of TSS ${ }^{(-0.1)}$ (Figure $13)$. 

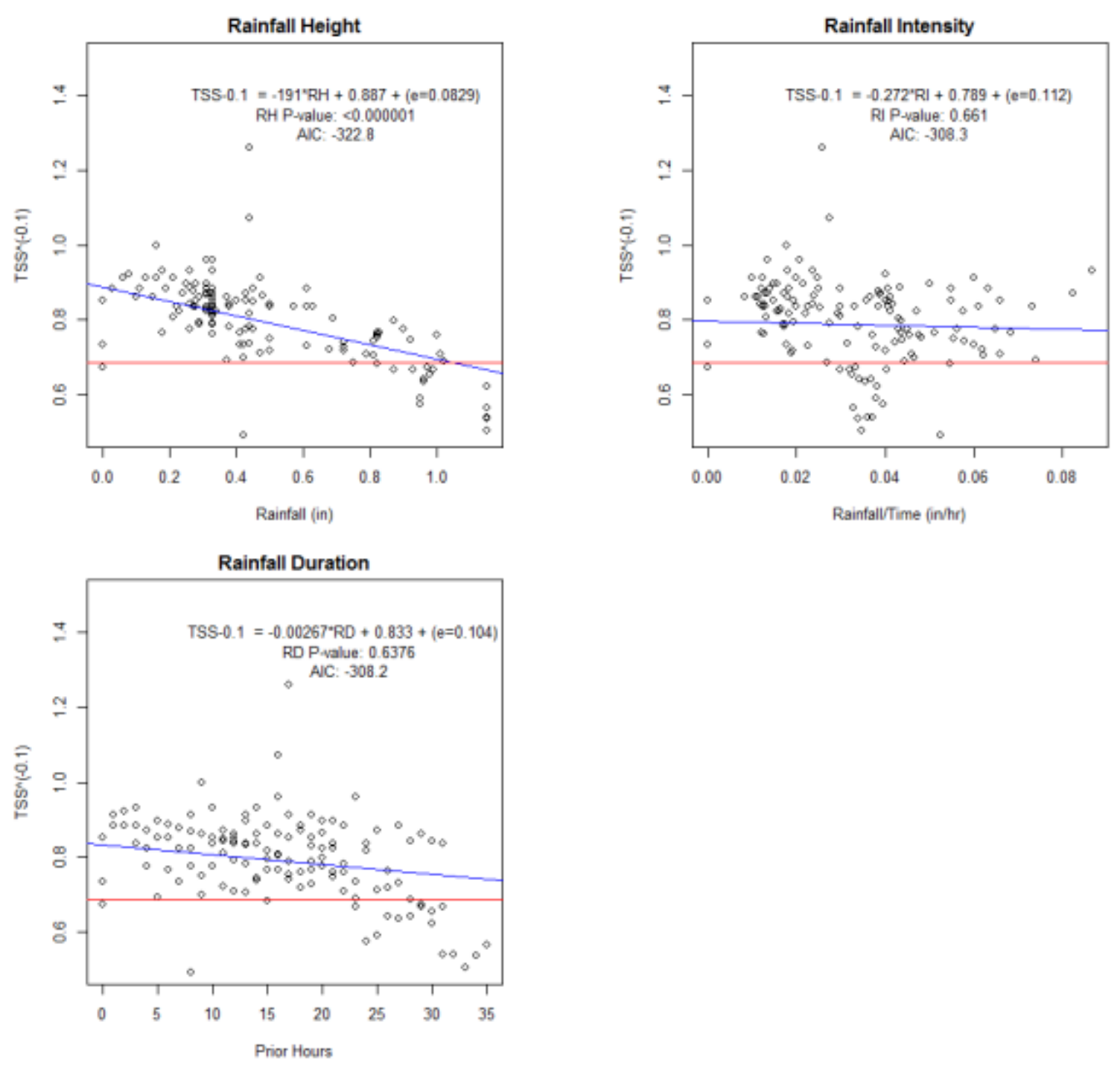

Figure 13: GLS plots of Rainfall Depth, Rainfall Intensity, and Rainfall Duration versus $\operatorname{TSS}^{\wedge}(-0.1)$ for the Autosampler measurements. Note that only the RH model have a P-value $<0.05$, indicating a significant relationship between $\mathbf{R H}$ and TSS ${ }^{(-0.1)}$. The RH model had the lowest AIC score. The blue line represents the GLS model, the points represent values of rainfall characteristics, and the red line represents $43 \mathrm{mg} / \mathrm{L}^{(-0.1)}$, or the boxcox transformed informal TSS threshold informed by BES and ODEQ. Note that points below the line represents exceeding the TSS informal threshold.

\subsection{Land Cover Summary}

The land cover characteristics of all the sub-basins delineated for the sampling locations within the McCarthy Creek watershed were very similar to one another, with uniformly high percentage tree cover with low variability $(\mathrm{C}$; mean $=70.7 \% ; \mathrm{CV}=6.69 \%$; Table 5$)$ and low impervious surface cover with extremely high variability $(\mathrm{I} ;$ mean $=1.49 \% ; \mathrm{CV}=72.5 \%$; Table 5). Variability was very high for 
slope, with intermediate $\mathrm{CV}$ values $\left(\mathrm{S} ;\right.$ mean $=13.7^{\circ} ; \mathrm{CV}=8.67 \%$; Table 5). Overall, variance and standard deviation were generally higher for independent variables in the mainstem locations compared to the tributaries (Table 5).

Table 5: Summary of mean TSS and mean Log TSS, Land Cover, and Mean Basin Slope for each Tributary and Mainstem (Segmented) sampling point of McCarthy Creek. Note that the highest standard deviation and variance were in mean TSS and Mean Basin Slope, while little standard deviation and variance were found in the Percentage Tree Canopy and Percentage Impervious Surface.

\begin{tabular}{|c|c|c|c|c|}
\hline Location & $\begin{array}{c}\text { Mean TSS } \\
(\mathrm{mg} / \mathrm{L})\end{array}$ & $\begin{array}{c}\text { Percentage Tree } \\
\text { Canopy }\end{array}$ & $\begin{array}{c}\text { Percentage Impervious } \\
\text { Surface }\end{array}$ & $\begin{array}{c}\text { Mean Basin Slope } \\
\text { (degrees) }\end{array}$ \\
\hline M1 & 104.7 & 68.2 & 1.96 & 12.1 \\
\hline $\mathrm{M} 2 \mathrm{U}$ & 77.8 & 67.2 & 1.04 & 13.8 \\
\hline M3U & 86.3 & 74.4 & 5.57 & 13.7 \\
\hline M5U & 95.8 & 65.6 & 0.54 & 13.4 \\
\hline M7 & 174.1 & 72 & 1.91 & 14 \\
\hline M8 & 194.9 & 64.4 & 1.62 & 14 \\
\hline Mainstem Mean & 122.27 & 68.6 & 2.11 & 13.5 \\
\hline Standard Deviation & 49.48 & 3.85 & 1.78 & 0.721 \\
\hline Mainstem CV & $40.5 \%$ & $5.56 \%$ & $84.7 \%$ & $5.34 \%$ \\
\hline $\mathrm{T} 2 \mathrm{E}$ & 89.4 & 78.3 & 1.6 & 13.25 \\
\hline T3E & 91.3 & 75.1 & 2.4 & 13.3 \\
\hline $\mathrm{T} 3 \mathrm{~W}$ & 72.9 & 68.3 & 0.62 & 15.6 \\
\hline $\mathrm{T} 4 \mathrm{~W}$ & 73.2 & 64.1 & 0.74 & 14.0 \\
\hline T5E & 71.8 & 72.2 & 0.2 & 11.0 \\
\hline $\mathrm{T} 5 \mathrm{~W}$ & 104.3 & 77 & 0.99 & 15.2 \\
\hline T6W & 55.9 & 71.8 & 0.16 & 14.4 \\
\hline Tributary Mean & 79.8 & 72.4 & 0.959 & 13.8 \\
\hline Tributary Standard Deviation & 16.1 & 4.99 & 0.804 & 1.52 \\
\hline Tributary CV & $20.1 \%$ & $6.90 \%$ & $83.9 \%$ & $11.0 \%$ \\
\hline Watershed Mean & 99.4 & 70.7 & 1.49 & 13.7 \\
\hline $\begin{array}{c}\text { Watershed Standard } \\
\text { Deviation }\end{array}$ & 40.4 & 4.74 & 1.414 & 1.19 \\
\hline Watershed CV & $14.9 \%$ & $6.70 \%$ & $95.0 \%$ & $8.67 \%$ \\
\hline
\end{tabular}




\subsubsection{Land Cover OLS and Spatial Regressions for Mean LogTSS Concentrations for Tributary and}

Mainstem Sampling Locations.

Land cover variables were not statistically significant predictors of mean LogTSS or any of the yields from the different peak flow regimes. Specifically, none of the OLS models displayed a statistically significant relationship between mean LogTSS concentrations and rainfall characteristics, percentage tree canopy, percentage impervious surface, and slope (Table 5; $p>0.05$ ).

The data in these models were fairly statistically robust. Both the data and the models passed all diagnostic tests including normal distribution (Shapiro-Wilks: $\mathrm{W}=0.95069, \mathrm{p}=0.736$ ), although spatial autocorrelation was statistically significant in the OLS models. Data displayed a tendency for dispersal rather than clustering due to a Moran's I value less than -0.5 with accompanying p-values less than 0.05 . However, neither a spatial error nor a spatial lag model could be used since all of the OLS models failed to display statistical significance (Tables A1-A3). The p-values greater than 0.05 from all of the OLS models would only be inflated and therefore be less significant if a Lagrange Multiplier was performed to eliminate autocorrelation.

Though none of the OLS models displayed any statistically significant relationships, the coefficients for the different rainfall characteristics were much higher than any of the land cover variables (Table 1A). Coefficient values for $\mathrm{C}$, I, and $\mathrm{S}$ were all less than 1 , indicating that the land cover variables would not have much of an impact on mean LogTSS concentrations even if the OLS and subsequent spatial lag and spatial error models proved significant (Table A1). 


\subsubsection{Land Coverage OLS and Spatial Regressions for Peak Flow Yields for Tributary and Mainstem}

Sampling Locations.

None of the land cover or rainfall characteristic variables were statistically significant predictors

of the 5, 10, and 25 year mean Log TSS Yields for the tributary or mainstem sampling locations, based on p-values $<0.05$ (Tables A2 and A3).

The coefficients for the prior rainfall periods were much higher than those for the land cover variables throughout the Watershed (Tables A2 and A3). The highest to lowest values of these land cover coefficients descend from C, I, to S in the tributary sampling locations (Table A2). Conversely, the highest to lowest coefficient values for the mainstem sampling locations were I, C, and S (Table A3). However, the magnitude of these coefficients cannot be used to predict the effects of each variable due to the lack of statistical significance of any of the models.

\section{Discussion}

\subsection{Spatial Extension TSS Concentrations and Yields During Storm Events}

The TSS concentration and yield values for the sampling locations were homogenous and elevated throughout the McCarthy Creek watershed during storm events. This was shown by the lack of statistically significant differences that would normally indicate hotspots. Therefore, there were no geographical or statistical trends in TSS concentrations and yields. Additionally, each location was homogenous in response to storm events, as they all would exceed the $43 \mathrm{mg} / \mathrm{L}$ TSS concentration informal threshold throughout the entire watershed whenever a storm occurred with RH of 0.15 over 24 hours (Figures 4 and 5; Tables 2-4).

The overall non-statistical trends for both the mean TSS concentrations and yields appear to be that of an upwards trajectory from upstream to downstream on the mainstem sampling locations (Figures 4 and 5). This was analogous to what would be expected in a less altered stream, as the headwaters act as 
a supply of sediment while depositing heavy sediment loads downstream (Allan and Castillo 2007; Davies 2008; Gomi et al. 2005). However, the McCarthy Creek mean TSS concentrations and yields were much higher than an undisturbed forested system and greatly exceeded the informal BES threshold of $43 \mathrm{mg} / \mathrm{L}$ for Willamette streams set by BES whenever a storm event with precipitation greater than $0.15 \mathrm{~cm}$ occurred (Figures 1 and 2; City of Portland BES 2015; Dodds and Whiles 2004; Goore Bi et al. 2015). This was likely due to either high sediment supply from the headwaters or high bank erosion and bed scouring rates prevalent in the more developed mainstem sections observed during sample collection (Allan and Castillo 2007; Schoonover et al. 2007; Gomi et al. 2005). The forested headwaters at M1 may be a source of TSS for the watershed as a whole but channel erosion rates due to urbanization may contribute to M2-M8 at the site level (Allan and Castillo 2007; Gomi et al. 2005; Singh and Chang 2014).

However, the ANOVA and paired t-tests for the main-stem and tributary sampling locations have determined that these differences and trends were not statistically significant. Given the structural differences of the stream throughout this watershed, the different lengths of tributaries and mainstem stretches, and the legacy of urbanization and natural resource use, I expected that at least one of them would have been different (Davie 2008; Biolatta and Brazier 2008). The absence of statistically significant differences runs contrary to similar studies that contrast geographical locations and TSS concentrations, which have often found significant differences among tributaries and mainstem sampling locations throughout different hydrological spatial-scales (Singh and Chang 2014; Henjum et al. 2010; Hatt et al. 2004; Coulter et al. 2004; Bell et al. 2016; Rosado-Berrios and Bouldin 2016; Uwimana et al. 2017).

The lack of differences indicate that the tributaries neither have a dilution nor a contributing effect to the mainstem TSS concentrations and yields (Morris et al. 2014). This was shown by the lack of differences in paired mainstem sampling locations, in which a significant increase would have indicated a contributing tributary versus a diluting tributary in which the opposite is true (Kreiling and Houser 2016; Table 2). Although there were no significant differences, the tributaries had much lower TSS 
concentrations and yields indicating that the tributaries are not overwhelmingly problematic and was more similar to an unaltered stream with high percentage tree canopy (Morris et al. 2014; Gomi et al. 2005; Table 5). This may indicate that past land use from logging and possibly mining is still having a large effect on TSS concentrations throughout McCarthy Creek, delaying the effects of cessation of both these activities and of the benefits of riparian restoration (Dodds and Whiles 2004; Jordan et al. 2013).

One potential explanation for the lack of differences of TSS concentration and yields and mainstem locations in this study and others referenced could be due to inherent autocorrelation from conducting mainstem studies. This would be on par with other TSS concentration and yield studies: Few eliminate autocorrelation and may have artificially inflated significant differences/relationships between sampling points (Uwimana et al. 2017; Squires et al. 2017; Rosado-Berrios and Bouldin et al. 2016; Kreiling and Houser et al. 2016; Jordan et al. 2014). For these studies, the statistical differences between mainstem sampling locations may have been more pronounced than they should have been. In contrast, the lack of statistical differences between any of the mainstem sampling locations in this study make autocorrelation moot: Autocorrelation should inflate statistical differences rather than minimize them. The actual differences among mainstem sampling locations in this study may actually be much lower than the already statistically insignificant differences present.

There are several potential sources of error for this segment of the study. First, the results could have been greatly influenced due to such a small sample size of storm events $(n=8)$. In comparison, Coulter et al. (2004) had n=26, while Murphy et al. (2015a) and Zhang et al. (2015) had n=27 over the course of six months to a year. This was due to the late project finalization that only allowed me to sample during February to June. I subsequently missed the first flush effects during the beginning of the fall and mid-winter (September to January) rainy season. If the first flush was included, TSS levels would likely be much higher since first flush mobilizes TSS loads that have been deposited along streambanks and impervious surface areas during long term dry conditions that would not have been present during the winter and spring rains (Squires et al. 2017; Vogel and Moore 2016; Murphy et al. 
2015). Second, the periodic timing of the samples may have underestimated TSS concentrations and yields. For example, Henjum et al. (2010) pointed out that grab samples in a bi-weekly or monthly basis caused lower estimates compared to daily sampling, although such fine resolution was temporally and financially infeasible for this project. Additionally, the lasting snow may have resulted in elevated TSS concentrations and yields throughout the sampling periods. Valtanen et al. (2015) had found that TSS will accumulate in snow banks and would only be released during high rates of melting or storm events that result in sheet run-off in late April or early spring in a watershed in Sweden. This may have occurred at the beginning of the sampling phase during February, when temperatures rose above freezing, and may have been different throughout the watershed. Lastly, the filters often ripped when samples were processed in large batches.

\subsection{Rainfall Characteristics, TSS Concentrations, and TSS Yields}

For the spatial extensive samples, RH and RI were found to be significantly related TSS concentrations in both the mainstem and tributary sampling locations. However, RH and RI were unexpectedly different in their responsiveness to TSS depending on location: the mainstem sampling locations were more responsive to RH while the tributary locations were more responsive to RI (Figures 9 and 10). Also, RD was only significantly related to TSS concentrations for the mainstem sampling locations (See Figures 9 and 10). In contrast to other studies, RD should have been significant in both mainstem and tributary sampling locations given that RD typically treated as a proxy of pollutant load that is representative in run-off to a creek (Zhang et al 2015). These results may be due to other land characteristics of McCarthy Creek as well as potential model error.

The conclusion that RH and RI were significantly related to TSS concentrations is similar to the conclusions from Borris et al. (2014) and Goore Bi et al. (2015). However, a number of other studies have found RI or RH differed in their significance to TSS: One was often more important factor than the other. 
For example, Murphy et al. (2015a) found that RI had a significant relationship with TSS concentrations while RH did not, and Goore Bi et al. (2015) found the opposite. This is despite the fact that both studies used mixed urbanized to residential watersheds for their studies, and the results did not differ between studies that incorporated both mainstem and tributary sampling sites or only tributary sites.

A possible explanation could be that the characteristics of TSS in the tributaries consists of particulates while the mainstem mostly consisted of finer, more dissolved TSS. Given that high RI often mobilizes large particulates much more than $\mathrm{RH}$, the tributaries may be similar to the natural distribution sediment that would intrinsically be more affected by RI in the headwaters, while the mainstem sampling points further downstream may be more impacted by RH (Murhpy et al. 2015; Allan and Castillo 2007). Additionally, the strength of the relationship between TSS, RH, and RI may be related to characteristics not analyzed in this study such as bank erosion or underlying geology (Gomi et al. 2005; Allan and Castillo 2007).

The lack of a significant relationship between RD and the tributary TSS concentrations is surprising, given that Squires et al. (2017) and Murphy et al. (2015a) found that RD had a significant effect on TSS concentrations, alongside RI or RH. However, the streams studied in these cases were much larger than the tributaries of McCarthy Creek. The tributaries may lose most of their TSS supply initially during a storm with high RI and RH, resulting in a low correlation between RD and TSS concentrations (Gomi et al .2005 and Allan and Castillo 2007). RD may be much more dependent on the scale of the watershed being studied, in which the mainstem may be large enough for RD to have a significant impact such as those found in Zhang et al. 2015 and Murphy et al. 2015a.

It is important to consider whether the results of the rainfall characteristics section could be due to errors in the regression models themselves: the mainstem sampling locations have high spatial autocorrelation in both TSS and rainfall characteristics due to being upstream and downstream from one another and are therefore not independent observations; this would result in artificially low p-values 
(Figure 8). However, the effects of autocorrelation should be similar among all rainfall characteristic models, so comparison between them can still effectively capture stream responsiveness.

The effects of autocorrelation may explain the differences in the statistical significance of rainfall characteristics between the tributary and mainstem sampling locations. RH may have an artificially inflated statistical significance due to autocorrelation in the mainstem sampling locations compared to the tributary sampling locations. Seemingly, autocorrelation should have affected the relationship for RI in a similar fashion. Perhaps autocorrelation may have affected RI less than RH for unknown reasons, which may be an explanation for why RI is more significant for tributary sampling locations.

Autocorrelation may be an explanation as to why RD is significant only for the mainstem models. Given that autocorrelation is not present in the tributary models, in which RD was rejected as a significant rainfall characteristic, the mainstem models may have had an artificially low p-value that resulted in a Type I error; RD was accepted as a statistically significant variable when it should not have been. RD's relationship may with TSS concentrations may be intrinsic to characteristics of a watershed not found in this study, as Squires et al. 2017 and Murhpy et al. 2015a had found that RD had a statistically significant relationship with TSS concentrations, while Borris et al. 2014; and Goor Bi et al. 2015 concluded the opposite despite studying watersheds with similar land cover. Overall, RD may not be a useful rainfall characteristic that explains TSS concentrations and loads for McCarthy Creek.

\subsection{Time Series \& TSS Concentration Results}

Though a significant relationship was found for all of the finalized GLS models, the RH model for the M7 downstream location had the lowest AIC score and was therefore the best-fit model that explained TSS concentrations (Figure 11). This was similar to the results found in the grab sample regression models for the mainstem locations in McCarthy Creek (Figure 6). Overall, TSS concentrations in McCarthy Creek were very responsive RH and much more responsive to storms events compared to 
results from watersheds in Mallin et al. (2009) and Borris et al. (2017). The significant relationship between RH specifically was also consistent with the results of Goore Bi et al. (2015) who found that total rainfall was significantly correlated with TSS event flux.

However, temporal autocorrelation is likely to be inherent for all of the models due to the nature of accumulating RH, RD, RI, and TSS throughout a single location during the course of a storm. Although GLS models are supposed to eliminate autocorrelation in temporal observations in hourly data, this is still likely influential as the p-values are extremely low (Figure 11). Additionally, GLS models may not be appropriate when grouped with separate storms on different dates. Conversely, the effects of temporal autocorrelation are likely to be the same for all of the GLS models in a similar fashion to the spatial autocorrelation in mainstem sampling locations, which would still make comparisons between the models viable.

The GLS models suffer from a low number of storms sampled due to instrument error $(n=6)$. There were frequent mechanical failures of the ISCO Autosampler 6700, likely due to wear and tear from its advanced age. Additionally, processing 48 samples from each storm had resulted in multiple ripped filters; sometimes an entire batch would be ruined if multiple batches were processed at the same time. If the autosampler and filters had worked out as planned, over 16 storms would have been sampled between January and June.

The location of the autosampler did not fully capture McCarthy Creek at its outlet to the Columbia River (Figure 1). This was due to the evidence of presence of transient individuals near the true outlet weighed against the monetary value of the autosampler. The dynamics between TSS concentrations and RH may have been different if the autosampler were placed at the true outlet versus further upstream: the property near it showed high signs of erosion combined with naturally high sediment deposition rates found at the outlet of an urbanized stream (Allan and Castillo 2007; Davies 2008; Gomi et al. 2005). 


\subsection{Land Use Cover \& TSS Concentrations and Yields}

Unexpectedly, none of the land cover variables was a statistically significant predictor of mean TSS concentrations and yields in any of the sub-watersheds of McCarthy Creek for any of the OLS regression equations (Table 5). This is in contrast to most studies that have a land cover component, which all concluded that there are significant relationships between land cover and TSS (Jarden et al. 2016; Jordan et al. 2014; Chen and Chang 2014). The low variation in TSS values was likely due to the lack of variation between land cover variables for each sub-watershed that was identified only after the study was conducted (high tree cover; low impervious surface area; low differences in slope Table 5).

\subsubsection{Impervious Surface Areas}

The lack of relationship between impervious surface areas and TSS concentrations and yields may be due to the low percentage of impervious surface cover. The actual percentage cover of impervious surface areas were actually very low with an overall mean of $1.4 \%$, despite the high $\mathrm{CV}$ values that exists for all of the sub-watershed (Table 5). Dodds and Whiles (2004) estimated that > 5\% impervious surface area was the threshold of when urbanized areas would affect TSS concentrations, and the only sub-watershed to exceed that threshold was M5U (Table 5). For studies that do display significant relationships between impervious surface areas or high urbanized surface areas, the watersheds under investigation had nearly $40 \%$ percentage impervious surface area (Chen and Chang 2014; Coulter et al. 2004; Bell et al. 2016). Overall, impervious surface areas may be so low that it would not be the main driver of high TSS concentrations and yields in McCarthy Creek (Dodds and Whiles 2004).

The age of the impervious surfaces in McCarthy Creek may also blunt the significant negative relationship with TSS. McCarthy Creek's impervious surface areas are decades old and may no longer be a significant source of TSS. Multiple studies conclude that the conversion to impervious surfaces is the 
main source of elevated TSS and sediment loads from an urban area (Hatt et al. 2004; Jordan et al. 2014). After the initial installation, the streams adjacent to impervious surface areas become supply limited as all of the loose material during conversion has been flushed out (Palmer et al. 2007; Hatt et al. 2004; Gomi et al 2004). Even though impervious surface areas can still be sources when material is deposited due to sheet runoff or atmospheric deposition, older areas are unlikely to be huge sources compared to internal sources such as bank erosion, landslides, and channelization (Zhang et al. 2015; Murphy et al. 2015a; Palmer et al. 2007). This is likely the case for the low impervious surface areas that exist in McCarthy Creek. Overall, disturbance rather than pre-existing impervious surface areas may be influential to TSS concentrations and yields.

\subsubsection{Tree Cover}

The lack of a significant relationship between tree cover and TSS is even more surprising given that most studies conclude the opposite. Often high tree cover is associated with lower TSS concentrations and yields when compared to an urbanized watershed with high impervious surface areas (Mallin et al. 2009; Rosado-Berrios and Bouldin 2016). This is more unexpected given that the total amount of tree cover for the sub-watersheds in McCarthy Creek was very high at $70 \%$ with little variation between them (Table 6). It is high enough that TSS concentrations and yields that could have been present from impervious surface areas were cancelled out by much higher tree cover values, given that it exceeds the Dodds and Whiles (2004) estimate of $20 \%$ tree cover minimum before extremely high TSS values became problematic (Rosado-Berrios and Bouldin 2016; Bell et al. 2016; Uwimana et al. 2017; Table 6). The TSS concentrations and yields of McCarthy Creek may be due to other factors that purely percentage tree cover and rainfall characteristics, such as the lack of variability and type of tree cover between sub-watersheds, the possibility that the forests of McCarthy Creek are TSS sources, and tree cover change may be more influential. 
The effectiveness of tree cover can be highly dependent on the type of composition of the plant community. Those considered to be later seral stages with a high percentage of evergreen trees is often touted as the best vegetation community for storm-water management control while majority deciduous forests that lose their leaves in the winter and invasive species were considered the worst (Palmer et al. 2007). However, this study did not distinguish between different communities as the NLCD 2011 Land Cover data used only counted total percentage area under tree canopy (USGS-NLCD 2011). If the land cover data were distinguished by the quality of botanical community, a relationship between tree cover and TSS values could be revealed.

Sometimes tree cover can actually be a source of TSS. Although there is a natural background level of sediment and thus TSS provided by forested headwaters, forestry management practices such as heavy logging or thinning can increase TSS concentrations and yields from runoff for years even after these activities cease (Allan and Castillo 2007; Gomi et al. 2004). However, the only management by Oregon Metro near the forested mouth of the watershed appears to have undergone a thinning treatment. Additionally, a number of studies actually combine agricultural land and tree cover together as vegetative cover. This can lead to overestimation of tree covers effects on TSS concentrations and loads, as agriculture is often a dominant source of TSS in a watershed (Mallin et al. 2009; Coulter et al. 2004).

Lastly, the change in tree cover instead of its presence may be more significantly related to TSS concentrations and yields. Jorden et al. (2013) had found that drastic changes in reforestation had a negative relationship with TSS concentrations and yields over the course of 15 years, while other studies had found extremely low tree cover from recently deforested areas to be highly correlated with TSS concentrations (Rosado-Berrios and Bouldin 2016). 


\subsubsection{Other Explanations}

The most likely source of the lack of relationships between land cover and TSS could be due to low variation in tree cover, impervious surfaces, and the lack of statistical differences in mean TSS concentrations and yields. The variation is so low for each that there simply could not be any statistical differences between any of the land cover values for the sub-watersheds (Table 5). Therefore, a relationship between rain, TSS concentrations and yields, and any of the land cover variables would be impossible to tease out (Vogt et al. 2016). There may even be the possibility that land cover may not have any noticeable effect on TSS concentrations and yields at all (Schoonover et al. 2007).

Another explanation for the lack of differences in TSS concentration and yield responses to land cover could be that the scale of the McCarthy Creek watershed is so small the entire stream response is synchronous, no matter where in the stream. Vogt et al.(2016) found that the scale of watersheds matters for in-stream water quality responses to precipitation despite land cover: those that were smaller often responded more homogenously than those that were larger. When conducting a study of McCarthy Creek at a smaller watershed scale (2851 acres) with relatively homogenous land cover throughout, land use might not be a significant factor (Singh and Chan 2014).

Also, the macro-invertebrate studies like those conducted by WMSWCD may not be the best indicator of water quality degradation from impervious surfaces. Given that Cuffney et al. (2010) had found a $14 \%$ decrease in species assemblages at relatively low (5\%) impervious surface area in a variety of Portland, OR streams that drain into the Willamette River, this implies that small changes in impervious area, even if they do not result in significant increases in TSS, can still adversely affect macro-invertebrates. Still, since the macro-invertebrate assembly in McCarthy Creek is degraded more severely than the impervious area would predict, this suggests that impervious surface areas are not the only explanation for degraded macro-invertebrate habitat quality. Therefore, the impervious surface areas 
Table 6: Soil types, acreage, percentage area, and surface soil erodibility factors for mainstem and tributary sub-basins. Note that most of the soil erodibility factors are near or exceed the k-factor threshold of 0.25 for "moderate" erodibility (MSU 2002).

\begin{tabular}{|c|c|c|c|c|c|c|c|c|c|}
\hline Sub-basin & Soil Type & Acres & $\%$ of Area & K-factor & Sub-basin & Soil Type & Acres & $\%$ of Area & K-factor \\
\hline \multirow[t]{5}{*}{ M1 } & $7 \mathrm{~B}$ & 1.7 & 0.7 & 0.24 & \multirow[t]{5}{*}{$\mathrm{T} 2 \mathrm{E}$} & $7 \mathrm{~B}$ & 2.4 & 1.5 & 0.24 \\
\hline & $7 \mathrm{C}$ & 59.8 & 25.7 & 0.24 & & $7 \mathrm{C}$ & 22.8 & 13.7 & 0.24 \\
\hline & $7 \mathrm{D}$ & 46.8 & 20.1 & 0.24 & & $7 \mathrm{D}$ & 16.3 & 9.7 & 0.24 \\
\hline & $7 \mathrm{E}$ & 6.9 & 3 & 0.24 & & $17 \mathrm{C}$ & 4.7 & 2.8 & 0.28 \\
\hline & $17 \mathrm{E}$ & 117.4 & 50.5 & 0.28 & & $17 \mathrm{E}$ & 121 & 72.4 & 0.28 \\
\hline \multirow[t]{8}{*}{ M2 } & $7 \mathrm{~B}$ & 34.9 & 4.3 & 0.24 & \multirow[t]{4}{*}{ T3E } & $7 \mathrm{C}$ & 7.4 & 8.9 & 0.24 \\
\hline & $7 \mathrm{C}$ & 68.1 & 8.3 & 0.24 & & $7 \mathrm{D}$ & 28.2 & 33.9 & 0.24 \\
\hline & $7 \mathrm{D}$ & 199.3 & 24.3 & 0.24 & & $17 \mathrm{C}$ & 1.4 & 1.7 & 0.28 \\
\hline & $7 \mathrm{E}$ & 1.3 & 0.2 & 0.24 & & $17 \mathrm{E}$ & 46.1 & 55.5 & 0.28 \\
\hline & $17 \mathrm{C}$ & 7.4 & 0.9 & 0.28 & \multirow[t]{7}{*}{$\mathrm{T} 3 \mathrm{~W}$} & $7 \mathrm{~B}$ & 5.4 & 5 & 0.24 \\
\hline & $17 \mathrm{D}$ & 24 & 2.9 & 0.28 & & $7 \mathrm{C}$ & 6.6 & 6.1 & 0.24 \\
\hline & $17 \mathrm{E}$ & 479.7 & 58.6 & 0.28 & & $7 \mathrm{D}$ & 26.9 & 24.9 & 0.24 \\
\hline & $43 \mathrm{C}$ & 4.5 & 0.5 & 0.32 & & $14 \mathrm{C}$ & 0.7 & 0.6 & 0.43 \\
\hline \multirow[t]{6}{*}{ M3U } & $7 \mathrm{~B}$ & 4.6 & 2 & 0.24 & & $17 \mathrm{C}$ & 0.7 & 0.6 & 0.28 \\
\hline & $7 \mathrm{C}$ & 27.4 & 12.1 & 0.24 & & $17 \mathrm{D}$ & 20.9 & 19.3 & 0.28 \\
\hline & $7 \mathrm{D}$ & 22.5 & 9.9 & 0.24 & & $17 \mathrm{E}$ & 46.9 & 43.4 & 0.28 \\
\hline & $17 \mathrm{C}$ & 21.7 & 9.5 & 0.28 & \multirow[t]{5}{*}{$\mathrm{T} 4 \mathrm{~W}$} & $7 \mathrm{C}$ & 12.8 & 8.5 & 0.24 \\
\hline & $17 \mathrm{D}$ & 17.8 & 7.8 & 0.28 & & $7 \mathrm{D}$ & 16.1 & 10.7 & 0.24 \\
\hline & $17 \mathrm{E}$ & 133.6 & 58.7 & 0.28 & & $17 \mathrm{C}$ & 1.6 & 1.1 & 0.28 \\
\hline \multirow[t]{7}{*}{ M5U } & $7 \mathrm{~B}$ & 5.1 & 1 & 0.24 & & $17 \mathrm{D}$ & 31.1 & 20.7 & 0.28 \\
\hline & $7 \mathrm{C}$ & 32.9 & 6.4 & 0.24 & & $17 \mathrm{E}$ & 88.6 & 58.9 & 0.28 \\
\hline & $7 \mathrm{D}$ & 82.7 & 16.1 & 0.24 & \multirow[t]{5}{*}{$\mathrm{T} 5 \mathrm{E}$} & $7 \mathrm{C}$ & 8.1 & 3.7 & 0.24 \\
\hline & $14 \mathrm{C}$ & 0.7 & 0.1 & 0.43 & & $7 \mathrm{D}$ & 0.6 & 0.3 & 0.24 \\
\hline & $17 \mathrm{C}$ & 80 & 15.5 & 0.28 & & $17 \mathrm{C}$ & 31.5 & 14.3 & 0.28 \\
\hline & $17 \mathrm{D}$ & 90.4 & 17.6 & 0.28 & & 17D & 87.1 & 39.4 & 0.28 \\
\hline & $17 \mathrm{E}$ & 223 & 43.3 & 0.28 & & $17 \mathrm{E}$ & 94 & 42.5 & 0.28 \\
\hline \multirow[t]{5}{*}{ M7 } & $7 \mathrm{C}$ & 39.5 & 4.3 & 0.24 & \multirow[t]{5}{*}{$\mathrm{T} 5 \mathrm{~W}$} & $7 \mathrm{C}$ & 10.3 & 15.2 & 0.24 \\
\hline & $7 \mathrm{D}$ & 15.9 & 1.7 & 0.24 & & $7 \mathrm{D}$ & 9.2 & 13.7 & 0.24 \\
\hline & $17 \mathrm{C}$ & 62.3 & 6.8 & 0.28 & & $17 \mathrm{C}$ & 4.9 & 7.2 & 0.28 \\
\hline & $17 \mathrm{D}$ & 319.4 & 34.8 & 0.28 & & $17 \mathrm{D}$ & 22.8 & 33.7 & 0.28 \\
\hline & $17 \mathrm{E}$ & 480.5 & 52.4 & 0.28 & & $17 \mathrm{E}$ & 20.4 & 30.2 & 0.28 \\
\hline \multirow[t]{9}{*}{ M8 } & $6 \mathrm{~B}$ & 7.6 & 5.6 & 0.32 & \multirow[t]{4}{*}{ T6W } & $7 \mathrm{C}$ & 11.7 & 4.3 & 0.24 \\
\hline & $17 \mathrm{D}$ & 19.7 & 14.4 & 0.28 & & $17 \mathrm{C}$ & 15.5 & 5.7 & 0.28 \\
\hline & $17 \mathrm{E}$ & 83.7 & 61.1 & 0.28 & & $17 \mathrm{D}$ & 149 & 54.9 & 0.28 \\
\hline & $19 \mathrm{E}$ & 4 & 3 & 0.2 & & $17 \mathrm{E}$ & 95.4 & 35.1 & 0.28 \\
\hline & $37 \mathrm{~B}$ & 2.5 & 1.8 & 0.32 & & & & & \\
\hline & $37 \mathrm{C}$ & 4.7 & 3.4 & 0.32 & & & & & \\
\hline & $37 \mathrm{D}$ & 4.6 & 3.4 & 0.32 & & & & & \\
\hline & 44 & 0.5 & 0.3 & 0.32 & & & & & \\
\hline & 55 & 9.6 & 7 & 0.32 & & & & & \\
\hline
\end{tabular}


found in the McCarthy Creek watershed are likely too low to be an explanation for such low macroinvertebrate assemblages.

Lastly, the soil profiles of McCarthy Creek may be prone to erosion regardless of land use. The $\mathrm{k}$-factor ${ }^{11}$, or the soil erodibility factor as defined by the USDA for the revised universal soil loss equation (RUSLE), was found to be moderate for the watershed as a whole (MSU 2002; Table 6). The surface soil erodibility factors mostly fall near or within the 0.25-0.45 range for moderate erodibility that is typical of loam-silt soils, with most watersheds containing at least $50 \%$ of soil types under a k-factor of 0.28 (MSU 2002; Green 1986; Tables 6). This is unsurprising given that most of the soil types are silt-loam mixtures (Green 1986). However, the moderate erodibility and lack of diversity in k-factors throughout the watershed may be an explanation for the lack of statistical differences in TSS concentrations and yields between each sub-basin (Table 6).

The entire watershed may be prone to moderate erosion and high TSS concentrations and loads with no noticeable hotspots. This may be the case despite high tree cover and low impervious surface areas (See Table 5). However, full RUSLE calculations should be conducted for each sub-basin before any conclusions can be made.

\subsection{Suggestions for Future Studies}

Although TSS is typically a useful proxy for other water quality indicators, it has a variety of flaws. To combat these flaws, there are a variety of other water quality indicators that could be used for future studies. For instance, turbidity could be used as a proxy for TSS. This is due to turbidity being easier to measure with less room for error, faster sample collection times, faster lab processing times, and lower processing costs; also, turbidity can accurately be converted to TSS (Dodds and Whiles 2004). However, turbidity can overestimate TSS in some cases due to influences from dissolved substances

${ }^{11}$ (ton*acre*hr)/(hundred acre-ft-tonf-in). Erosion from a unit plot of $72.6 \mathrm{ft}$ long, $9 \%$ slope (USDA 2001) 
(Bilootta and Brazier 2008). Because turbidity also encompasses dissolved inorganic and organic components, sediment concentration estimates based on turbidity may be much higher than directly measured concentrations (Biolotta and Brazier 2008; Allan and Castillo 2007).

If sediment is measured directly, suspended sediment concentrations (SSC) may be more accurate than TSS as that approach do not have the same shortcomings. First and foremost, TSS only captures an aliquot that may underestimate the larger particles if not agitated well enough (Clark and Siu 2008; Gray et al. 2000). An aliquot that misses larger particles can lead to TSS concentrations that are systematically lower than what would be found using SSC (Clark and Siu 2008; Grey et al. 2000). In contrast, SSC captures the entirety of the sample, and may be a better sediment indicator by capturing all of the contents of the bottle (Gray et al. 2000).

However, only the USGS uses SSC extensively for their water quality and sediment studies, while PAWMAP, ODEQ, and local municipalities uses TSS. Given the focus on TSS as an indicator of sediment and sewage, choosing SSC as the main water quality indicator may render inter-agency collaboration more difficult given the two are not necessarily comparable. Adoption of SSC may also make historical comparisons to past TSS values nearly impossible (Clark and Siu 2008).

Lastly, a study that examines RUSLEs for each mainstem and tributary sub-basins is highly recommended. Considering that the k-factors indicate moderate erodibility for all sub-basins in McCarthy Creek, and few differences exist between k-factors of each sub-basin, the watershed as a whole may be prone to erosion. This could be based on existing soil characteristics and more micro-level land management that are present in the RUSLE model rather than rainfall characteristics and land cover used in this study (USDA 2001). 


\subsection{Suggestions for the WMSWCD}

The planting sites should act as sediment buffers to prevent transport of overland flow. However, the current WMSWCD's efforts may have too little planting acreage that is too recent to affect the watershed (Jarden et al. 2016; Gomi et al. 2005; Palmer et al. 2007). The geographical distribution of mean TSS concentrations and yields, the fact that TSS concentrations mostly exceed the informal BES threshold of $43 \mathrm{mg} / \mathrm{L}$ whenever a storm greater than $0.15 \mathrm{in}$. occurs, qualitative observations of site-scale bank erosion, and the declaration by some residents that fish were coming back indicates that certain areas of McCarthy Creek at the watershed scale would benefit from additional restoration efforts (Figures 1-4). Therefore, my recommendations to the WMSWCD are:

1. Continue restoration efforts along the mainstem, especially in properties near M2U and M2D that have not yet signed on as partners and aggressively interplant at M8

2. Work with Oregon Metro to plant woody vegetation in Metro property that contains M7

3. Purchase a turbidity meter and measure in-stream turbidity during the winter, including both during storms with rainfall $>0.15$ in. and during winter baseflow conditions, given that turbidity meters take less time and are a cheaper investment overall due to the lack of sample processing, relating turbidity to TSS would improve data collection while being as informative.

4. Conduct a future study using the RUSLE model for each sub-basin based on the USDA soil data to predict sediment yields and compare the results to the TSS yields from this study as an alternative to determine potential hotspots

5. Talk to the long-term residents about the location and magnitude of past land management activities. This includes logging and mining.

\subsection{Conclusions}

Overall, McCarthy Creek behaves like an urbanized watershed in terms of TSS concentrations and yields, but does not contain the same mechanisms as a highly developed one. Given the responsiveness to rainfall depth and lack of statistically significant differences in the sampling locations, McCarthy Creek seems to behave very similarly to a canal in which a storm event produces high TSS concentrations and yields throughout the entirety of the watershed (Gomi et al. 2005; Palmer et al. 2007). 
Additionally, given that there was no relationship between TSS and land cover variables (low percentage of impervious surface areas and the high percentage tree cover throughout the watershed), the source of high TSS concentrations and yields may be due to internal mechanisms of the stream. Specifically, it may be due mostly to bank erosion, stream bed scouring, upland forest management activities such as prior logging and/or thinning, or perhaps even the underlying geology and soil characteristics as noted above (Gomi et al. 2005; Allan and Castillo 2007; Table 6). Therefore, restoration may need to focus on preventing erosion and horizontal buffering with higher densities of shrubs and smaller trees to improve root mass rather than Tree Canopy. 


\section{References}

Allan, J.D. 2004. Landscapes and Riverscapes: The Influence of Land Use on Stream

Ecosystems. Annual Review of Ecology, Evolution, and Systematics 35: 257-284.

Allan, J.D. and Castillo, M. M. 2007. Stream Ecology: Structure and Function of Running Waters. $2^{\text {nd }}$ fed. Dordrecht (NE): Springer Publishing.

Abrams, Peter. Personal Communication. April 262016.

American Public Health Association (APHA), American Water Works Association, and Water Environment Federation. (2005). "Standard methods for the examination of water and wastewater.” APHA, Washington, DC.

Bell, C. D., McMillan, S. K., Clinton, S.M., and Jefferson, A.J. 2016. Hydrological response to stormwater measures in urban areas. Journal of Hydrology 541: 1488-1500.

Bilotta, G.S. and Brazier, R.E. 2008. Understanding the influence of suspended solids on water quality and aquatic biota. Water Research, 42(12): 2849-2861.

Borris, M., Viklander, M., Gustafsson, A., and Marsalek, J. 2014. Modelling the effects of the changes in rainfall characteristics on TSS loads in urban runoff. Hydrological Processes 28: 1787-1796.

Charters, F. J., T. A. Cochrane, and A. D. O'Sullivan. 2016. Untreated runoff quality from roof and road surfaces in a low intensity rainfall climate. Science of The Total Environment, 550: 265272.

Chen, H.J. and Chang, H. 2014. Response of discharge, TSS, and E. coli to rainfall events in urban, suburban, and rural watersheds. Environmental Science Processes \& Impacts, 16 (10): 2313-2324.

City of Portland Bureau of Environmental Services. 2015. Portland Area Watershed Monitoring and Assessment Program Executive Summary - First Year Data (2010-2011): Accessed February 2016, at https://www.portlandoregon.gov/bes/article/493158.

Coulter, C.B., Kolka, R.K., and Thompson, J.A. 2004. Water quality in agricultural, urban, and mixed land use watersheds. Journal of the American Water Resources Association 40 (6): 1593-1601.

Clark, S. E., and C. Y. S. Siu. 2008. Measuring Solids Concentration in Stormwater Runoff: Comparison of Analytical Methods. Environmental Science \& Technology, 42 (2): 511-516.

Cuffney, T. F., Brightbill, R. A., May, J. T. and Waite, I. R. (2010), Responses of benthic macroinvertebrates to environmental changes associated with urbanization in nine metropolitan areas. Ecological Applications, 20: 1384-1401. doi:10.1890/08-1311.

Davie, T. 2008. Routledge Fundamentals of Physical Geography: Fundamentals of Hydrology. 2nd ed. New York (NY): Routledge publishing.

Dodds W.K., and Whiles, M.R. 2004. Quality and quantity of suspended particles in rivers: continentscale patterns in the United States. Environmental Management 33 (3): 355-367. 
Environmental Protection Agency. 1997. Method 160.2: Residue, Non-Filterable Gravimetric, Dried at 103-105 ${ }^{\circ}$. Accessed August 2016, at http://www.caslab.com/EPA-Methods/PDF/EPA-Method160-2.pdf

Franczyk, J. Chang, H. 2008. The Effects of Climate Change and Urbanization on the Runoff of the Rock Creek Basin in the Portland Metropolitan Area, Oregon, USA. Hydrological Processes 23: 805-815.

Gall, S. 2015. 2015 Water Quality Monitoring Program Overview. West Multnomah Soil \& Water Conservation District. Retrieved September 2016, at https://wmswcd.org/wp-content/uploads/2016/03/WMSWCD-Water-QualityMonitoring-Program-Overview-02.2016.pdf?f3148f

Scott Gall, 2016. 2016 Water Quality Monitoring Report 2016. Retrieved from: https://wmswcd.org/wpcontent/uploads/2017/04/2016-WMSWCD-Water-Quality-Monitoring-Report.pdf

Gomi, T., Moore, R.D., and Hassan, M.A. 2015. Suspended sediment dynamics in small forest streams of the pacific northwest. Journal of the American Water Resources Association 41 (4): 877-898.

Goore Bi, E., Monette F., Gasperi, J. 2005. Analysis of the influence of rainfall variables on urban effluents concentrations and fluxes in wet weather. Journal of Hydrology 523: 320-332.

Gray, J.R., Glysson, G.D., Turcios, T.M., and Schwarz, G.E. 2000. Comparability of suspendedsediment concentration and total suspended solids data. United States Geological Service.

Green, G. L. 1983. Soil Survey of Multnomah County, Oregon. United States Soil Conservation Service.

Hatt, B. E., T. D. Fletcher, C. J. Walsh, and S. L. Taylor. 2004. The Influence of Urban Density and Drainage Infrastructure on the Concentrations and Loads of Pollutants in Small Streams. Environmental Management, 34 (1): 112-124.

Henjum, M. B., R. M. Hozalski, C. R. Wennen, P. J. Novak, and W. A. Arnold. 2010. A comparison of total maximum daily load (TMDL) calculations in urban streams using near real-time and periodic sampling data. Journal of Environmental Monitoring 12 (1): 234-241.

Homer, C., Huan, C., Yan, L., Wylie, B., and Coan, M. 2004. Development of a 2001 national landcover database for the United States. Photogrammertic Engineering \& Remote Sensing 70 (7): 829-840.

Jarden, K.M., Jefferson, A.J., and Grieser J.M. 2015. Assessing the effects of catchment-scale urban green infrastructure retrofits on hydrograph characteristics. Hydrological Processes 30 (10): 1536-1550.

Jordan, Y.C., Ghulam, A., and Hartling, S. 2014. Traits of surface water pollution under climate and land use changes: a remote sensing and hydrological modeling approach. Earth-Science Reviews 128: $181-195$.

Kreiling R.M., and Houser, J.N. 2016. Long-term decreases in phosphorus and suspended solids but not nitrogen, in six upper Mississippi River tributaries, 1991-2014. Environmental Monitoring Assessment 188 (545): 1-19/ 
Mallin, M. A., V. L. Johnson, and S. H. Ensign. 2009. Comparative impacts of stormwater runoff on water quality of an urban, a suburban, and a rural stream. Environmental Monitoring and Assessment, 159 (1-4): 475-491.

Metro Parks and Nature, 2016. North Tualatin Mountains Access Master Plan. Retrieved from: http://www.oregonmetro.gov/sites/default/files/North-Tualatin-Mountains-Access-MasterPlan.pdf

Michigan State University Institute of Water Resources, 2002. RUSLE: Online Soil Assessment Tool. Retrieved from: http://www.iwr.msu.edu/rusle/kfactor.htm

Morris, D. M., Gemeinhardt, T.R., Gosch, N.J.C., Jensen, D.E. 2014. Water quality during two highflow years on the lower Missouri River: The effects of reservoir and tributary connections. River Research and Applications 30: 1024-1033.

Multnomah County Road Services. 2010. Water Quality Monitoring Report: Westside Stream Monitoring for the Tualatin TMDL. Gresham, OR.

Murphy L.U., Cochrane, T.A., and O’Sullivan, A. 2015a. Build-up and wash-off dynamics of atmospherically derived $\mathrm{Cu}, \mathrm{Pb}, \mathrm{Zn}$, and TSS in stormwater runoff as a function of meteorological characteristics. Science of the Total Environment 508: 206-213.

Murphy, L.U., Cochrane, T.A., and O'Sullivan, A. 2015b. The influence of different pavement surfaces on atmospheric copper, lead, zinc, and suspend solid attenuation and wash-off. Water Air Soil Pollution: 226-232.

Oregon Department of Environmental Quality. 2006. Willamette Basin TMDLS. Chapter 5: Lower Willamette Subbasin TMDL. Pp: 5-1 to 5-198.

Palmer, M.J., Allan, D., Meyer, J., and Bernhardt, E.S. 2007. River Restoration in the Twenty- First Century: Data and Experiential Knowledge to Inform Future Efforts. Restoration Ecology 15: 472-481.

Patterson, H. 2010. 2010 Water Quality Biomonitoring Report. West Multnomah Soil \& Water Conservation District.

Rosado-Berrios, C. and Bouldin, J. 2016. Turbidity and Total Suspended Solids on the Lower Cache River Watershed, AR. Bulletin of Environmental Toxicology 96: 738-743

Rossi, L., Chevre, N., Frankhauser, R., Margot, J., Curdy, R., Babut, M., and Barry D.A. Sediment contamination assessment in urban areas based on total suspended solids. Water Research 47: 339-350.

RStudio Team. 2015. RStudio: Integrated Development for R. RStudio, Inc., Boston, MA URL http://www.rstudio.com/.

Schoonover, J.E., Lockaby, B.G., Shaw, J.N. 2007. Channel morphology and sediment origin in streams draining the Georgia Piedmont. Journal of Hydrology 342 (1): 110-123.

Shoredits A.S., and Clayton J.A. 2013. Assessing the practice and challenges of stream restoration in 
urbanized environment of the USA. Geography Compass 7/5: 358-372.

Singh, S., and H. Chang. 2014. Effects of Land Cover Change on Water Quality in Urban Streams at Two Spatial Scales. International Journal of Geospatial and Environmental Research 1 (1): Article 8: 1-21.

Squires A.L., Boll, Jan., Brookes, E.S. 2017. On the role of spatial, temporal, and climatic forces on stream sediment loading from rural and urban ecosystems. Journal of American Water Resources association. 00(0):1-17

Standard Methods for the Examination of Water and Wastewater, 20th ed.; Clesceri, L. S., Greenberg, A. E., Eaton, A. D., Eds.; American Public Health Association, American Water Works Association, Water Environment Federation: New York, 1999.

Sun, S., Barraud, S., Castebrunet H., Aubin, J., and Marmonier, P. 2015. Long-term stormwater quantity and quality analysis using continuous measurements in an urban catchment. Water Research 85: 432-442.

United States Department of Agriculture, 2001. Revised Universal Soil Loss Equation Version 2 Handbook. Retrieved from https://www.nrcs.usda.gov/Internet/FSE_DOCUMENTS/nrcs144p2_025079.pdf

United States Geology Service-HYDRA, 2017. City of Portland HYDRA Rainfall Network. Retrieved from https://or.water.usgs.gov/precip/index.html

United States Geological Service, 2017. National Land Cover Database, 2011 edition. Retrieved from: https://www.mrlc.gov/nlcd11_data.php

United States Geological Service-Streamstats, 2017. Streamstats batch processing tool, 2017. Retrieved from: https://streamstatsags.cr.usgs.gov/ss_bp/

Uwimana, A., Dam, A.V., Gettel, G., Bigirimana, R., and Irvine, K. 2017. Effects of river discharge and land use and land cover (LULC) on water quality dynamics in migina catchment, Rwanda. Environmental Management 60 (3): 496-515.

Valtanen, M., Sillanpaa, N., and Setala, H. 2015. Key factors affecting urban runoff pollution under cold climatic conditions. Journal of Hydrology 529: 1578-1589.

Vogel, J.R., and Moore, T.L. 2016. Urban stormwater characterization, control, and treatment. Water Environment Research 88 (10): 1918-1950.

Vogt, R.J., Frost, P. C., Neinhuis, S., Woolnough, D.A., Xenopoulous, M.A. 2016. The dual synchronizing influences of precipitation and land use on stream properties in a rapidly urbanizing watershed. Ecosphere 7 (9): 1-15.

Zhang, W., Li, T., and Dai, M. 2015. Influence of rainfall characteristics on pollutant wash-off for road catchments in urban Shanghai. Ecological Engineering 81: 102-106. 


\section{Appendix}

Table A1: Ordinary Least Square models for mean LogTSS using Percentage Tree Canopy (C), Percentage Impervious Surface (I), Mean Basin Slope (S), RH, RD and RI for the tributary and mainstem sampling locations. Note that all models have a P-value $>0.05$, indicating that the OLS models were not significant and no further spatial regression was necessary.

\begin{tabular}{|c|c|c|c|c|}
\hline Model & $\begin{array}{c}\text { F- } \\
\text { Statistics }\end{array}$ & $\begin{array}{c}\text { P- } \\
\text { Value }\end{array}$ & $\begin{array}{c}\text { Adjusted } \\
\mathbf{R}^{2}\end{array}$ & AIC \\
\hline \multicolumn{5}{|l|}{ Tributaries } \\
\hline $\begin{array}{c}\text { Mean LogTSS }=-14.81+26.48 * \mathrm{RH}-0.01239 * \mathrm{C}+0.02213 * \mathrm{I}-0.3215 * \mathrm{~S}+\left(\varepsilon^{1}=\right. \\
0.09165)\end{array}$ & 2.721 & 0.4229 & 0.5793 & -0.4770 \\
\hline Mean LogTSS $=13.68-336.7 * \mathrm{RI}-0.007483 * \mathrm{C}-0.03266 * \mathrm{I}+0.1534 * \mathrm{~S}+\left(\varepsilon^{1}=0.1155\right.$ & 0.05027 & 0.9888 & -3.163 & 13.28 \\
\hline $\begin{array}{c}\text { Mean LogTSS }=-15.23+0.7604 * \mathrm{RD}+0.001607 * \mathrm{C}+0.008552 * \mathrm{I}-0.2763 * \mathrm{~S}+\left(\varepsilon^{1}=\right. \\
0.1117)\end{array}$ & 1.247 & 0.5789 & 0.1648 & 3.638 \\
\hline \multicolumn{5}{|l|}{ Mainstem } \\
\hline $\begin{array}{c}\text { Mean LogTSS }=12.98-9.380 * \text { RH }-0.007734 * \mathrm{C}+0.1506 * \mathrm{I}-0.01025 * \mathrm{~S}+\left(\varepsilon^{1}=0 .\right. \\
0.06128)\end{array}$ & 0.5518 & 0.7248 & -0.4262 & -0.4847 \\
\hline Mean LogTSS $=15.58-338.2 * R I-0.01824 * C+0.2628 * I-0.02683 * S+\left(\varepsilon^{1}=0.6064\right)$ & 0.3348 & 0.8392 & -0.7968 & 1.133 \\
\hline Mean LogTSS $=10.74-0.2041 * \mathrm{RD}-0.009175^{*} \mathrm{C}-0.1033^{*} \mathrm{I}-0.01286^{*} \mathrm{~S}+\left(\varepsilon^{1}=\right.$ & 0.3629 & 0.8231 & -0.7383 & 0.9007 \\
\hline
\end{tabular}

$0.1217)$

Table A2: Ordinary Least Square models for mean Log Peak Yields (5 year, 10 year, 25 year scenarios) using Percentage Tree Canopy (C), Percentage Impervious Surface (I), Mean Basin Slope (S) RH, RD and RI for the mainstem sampling locations. Note that all models have a P-value >0.05, indicating that the OLS models were not significant and no further spatial regression was necessary.

\begin{tabular}{|c|c|c|c|c|}
\hline Model & $\begin{array}{c}\text { F- } \\
\text { Statistics }\end{array}$ & $\begin{array}{c}\text { P- } \\
\text { Value }\end{array}$ & $\begin{array}{c}\text { Adjusted } \\
\mathbf{R}^{2}\end{array}$ & AIC \\
\hline $\begin{array}{c}\text { Mean Log } 5 \text { Year Peak Flow TSS Yields }=-15.48+26.47 * \mathrm{RH}-0.04209+0.1053 * \mathrm{I}- \\
0.2954 * \mathrm{~S}+\left(\varepsilon^{1}=0.003678\right)\end{array}$ & 48.19 & 0.1076 & 0.9742 & -17.36 \\
\hline $\begin{array}{c}\text { Mean Log } 5 \text { Year Peak Flow TSS Yields }=30.47-904.9 * R I-0.02520 * C+0.02643 * I- \\
0.1331 * S+\left(\varepsilon^{1}=0.4867\right)\end{array}$ & 0.1160 & 0.9574 & -2.415 & 11.96 \\
\hline $\begin{array}{c}\text { Mean Log } 5 \text { Year Peak Flow TSS Yields }=-16.58+0.7885 * \mathrm{RD}-0.02750 * \mathrm{C}- \\
0.09268 * \mathrm{I}-0.2671 * \mathrm{~S}+\left(\varepsilon^{1}=0.02680\right)\end{array}$ & 6.397 & 0.2873 & 0.8119 & -5.439 \\
\hline $\begin{array}{c}\text { Mean Log } 10 \text { Year Peak Flow TSS Yields }=-15.27+26.34 * \mathrm{RH}-0.04097 * \mathrm{C}- \\
0.1027 * \mathrm{I}-0.2920 * \mathrm{~S}+\left(\varepsilon^{1}=0.003895\right)\end{array}$ & 45.06 & 0.1112 & 0.9724 & -17.01 \\
\hline $\begin{aligned} \text { Mean Log } 10 \text { Year Peak Flow TSS Yields }=30.25-894.1 * \mathrm{RI}-0.02430 * \mathrm{C}+0.02454 * \mathrm{I} \\
+0.1349 * \mathrm{~S}+\left(\varepsilon^{1}=0.4830\right)\end{aligned}$ & 0.1153 & 0.9578 & -2.4217 & 11.91 \\
\hline $\begin{array}{c}\text { Mean Log } 10 \text { Year Peak Flow TSS Yields }=-16.36+0.7842 * \mathrm{RD}-0.02646 * \mathrm{C}+ \\
0.09017 * \mathrm{I}-0.2637 * \mathrm{~S}+\left(\varepsilon^{1}=0.02720\right)\end{array}$ & 6.237 & 0.2907 & 0.8073 & -5.350 \\
\hline $\begin{array}{c}\text { Mean Log } 25 \text { Year Peak Flow TSS Yields }=-14.96-26.13 * \mathrm{RH}-0.04045 * \mathrm{C}-0.1009 * \mathrm{I} \\
-0.2880 * \mathrm{~S}+\left(\varepsilon^{1}=0.003838\right)\end{array}$ & 45.11 & 0.1112 & 0.9724 & -17.10 \\
\hline $\begin{aligned} \text { Mean Log } 25 \text { Year Peak Flow TSS Yields } & =30.20-887.0 * \mathrm{RI}-0.02391 * \mathrm{C}+ \\
0.02338 * \mathrm{I}+0.1356 * \mathrm{~S}+\left(\varepsilon^{1}=0.4755\right) & \end{aligned}$ & 0.1161 & 0.9574 & -2.414 & 11.82 \\
\hline $\begin{array}{c}\text { Mean Log } 25 \text { Year Peak Flow TSS Yields }=-16.04+0.7780 * \mathrm{RD}-0.02605 * \mathrm{C}+ \\
0.08849 * \mathrm{I}-0.2599 * \mathrm{~S}+\left(\varepsilon^{1}=0.02679\right)\end{array}$ & 6.249 & 0.2904 & 0.8077 & -5.442 \\
\hline
\end{tabular}


Table A3: Ordinary Least Square models for mean Log Peak Yields (5 year, 10 year, 25 year scenarios) using Percentage Tree Canopy (C), Percentage Impervious Surface (I), Mean Basin Slope (S) RH, RD and RI for the tributary sampling locations. Note that all models have a P-value >0.05, indicating that the OLS models were not significant and no further spatial regression was necessary.

\begin{tabular}{|c|c|c|c|c|}
\hline Model & $\begin{array}{c}\text { F- } \\
\text { Statistics }\end{array}$ & $\begin{array}{c}\text { P- } \\
\text { Value }\end{array}$ & $\begin{array}{l}\text { Adjusted } \\
\mathbf{R}^{2}\end{array}$ & AIC \\
\hline $\begin{array}{c}\text { Mean Log } 5 \text { Year Peak Flow TSS Yields }=0.4500-2.036 * \mathrm{RH}+0.02785 * \mathrm{C}- \\
0.04088 * \mathrm{I}+0.0002551 * \mathrm{~S}+\left(\varepsilon^{1}=0.1062\right)\end{array}$ & 0.4340 & 0.7841 & -0.6060 & 0.5412 \\
\hline $\begin{array}{c}\text { Mean Log } 5 \text { Year Peak Flow TSS Yields }=-25.22+744.2 * R I+0.03770 * C-0.2762 * I \\
+0.01299 * S+\left(\varepsilon^{1}=0.08661\right)\end{array}$ & 0.6443 & 0.6830 & -0.3108 & -0.8804 \\
\hline $\begin{array}{c}\text { Mean Log } 5 \text { Year Peak Flow TSS Yields }=3.003-0.1474 * \mathrm{RD}+0.02958 * \mathrm{C}- \\
0.07748 * \mathrm{I}-0.003639 * \mathrm{~S}+\left(\varepsilon^{1}=0.1032\right)\end{array}$ & 0.5192 & 0.7405 & -0.4718 & 0.06994 \\
\hline $\begin{aligned} \text { Mean Log } 10 \text { Year Peak Flow TSS Yields }=6.631-6.099 * \mathrm{RH}+0.01436 * \mathrm{C}+0.1331 * \mathrm{I} \\
+2.776 \mathrm{e}-005 * \mathrm{~S}+\left(\varepsilon^{1}=0.2434\right)\end{aligned}$ & 0.5491 & 0.7261 & -0.4298 & 1.3133 \\
\hline $\begin{array}{c}\text { Mean Log } 10 \text { Year Peak Flow TSS Yields }=-0.3718+6.195 * \mathrm{RI}+0.01777 * \mathrm{C} \\
+0.1093 * \mathrm{I}+0.02937 * \mathrm{~S}+\left(\varepsilon^{1}=0.1059\right)\end{array}$ & 0.6740 & 0.6704 & -0.2777 & 0.5259 \\
\hline $\begin{array}{l}\text { Mean Log } 10 \text { Year Peak Flow TSS Yields }=7.185-0.2009 * \mathrm{RD}+0.01477 * \mathrm{C}+ \\
0.08490 * \mathrm{I}+0.0292798 * \mathrm{~S}+\left(\varepsilon^{1}=0.1099\right)\end{array}$ & 0.6305 & 0.6890 & -0.3269 & 0.7905 \\
\hline $\begin{array}{c}\text { Mean Log } 25 \text { Year Peak Flow TSS Yields }=6.923-6.236 * \mathrm{RH}+0.01467 * \mathrm{C}+0.1345 * \mathrm{I} \\
+0.02918 * \mathrm{~S}+\left(\varepsilon^{1}=0.1094\right)\end{array}$ & 0.6717 & 0.6714 & -0.2802 & 0.7345 \\
\hline $\begin{array}{c}\text { Mean Log } 25 \text { Year Peak Flow TSS Yields }=6.279-150.908 * \mathrm{RI}+0.008782 * \mathrm{C}+ \\
0.1856 * \mathrm{I}+0.02015 * \mathrm{~S}+\left(\varepsilon^{1}=0.1207\right)\end{array}$ & 0.5280 & 0.7212 & -0.4161 & 1.440 \\
\hline $\begin{array}{c}\text { Mean Log } 25 \text { Year Peak Flow TSS Yields }=7.429-0.2033 * \mathrm{RD}+0.01505 * \mathrm{C}+ \\
0.08578 * \mathrm{I}+0.02904 * \mathrm{~S}+\left(\varepsilon^{1}=0.1135\right)\end{array}$ & 0.6260 & 0.6909 & -0.3322 & 1.013 \\
\hline
\end{tabular}



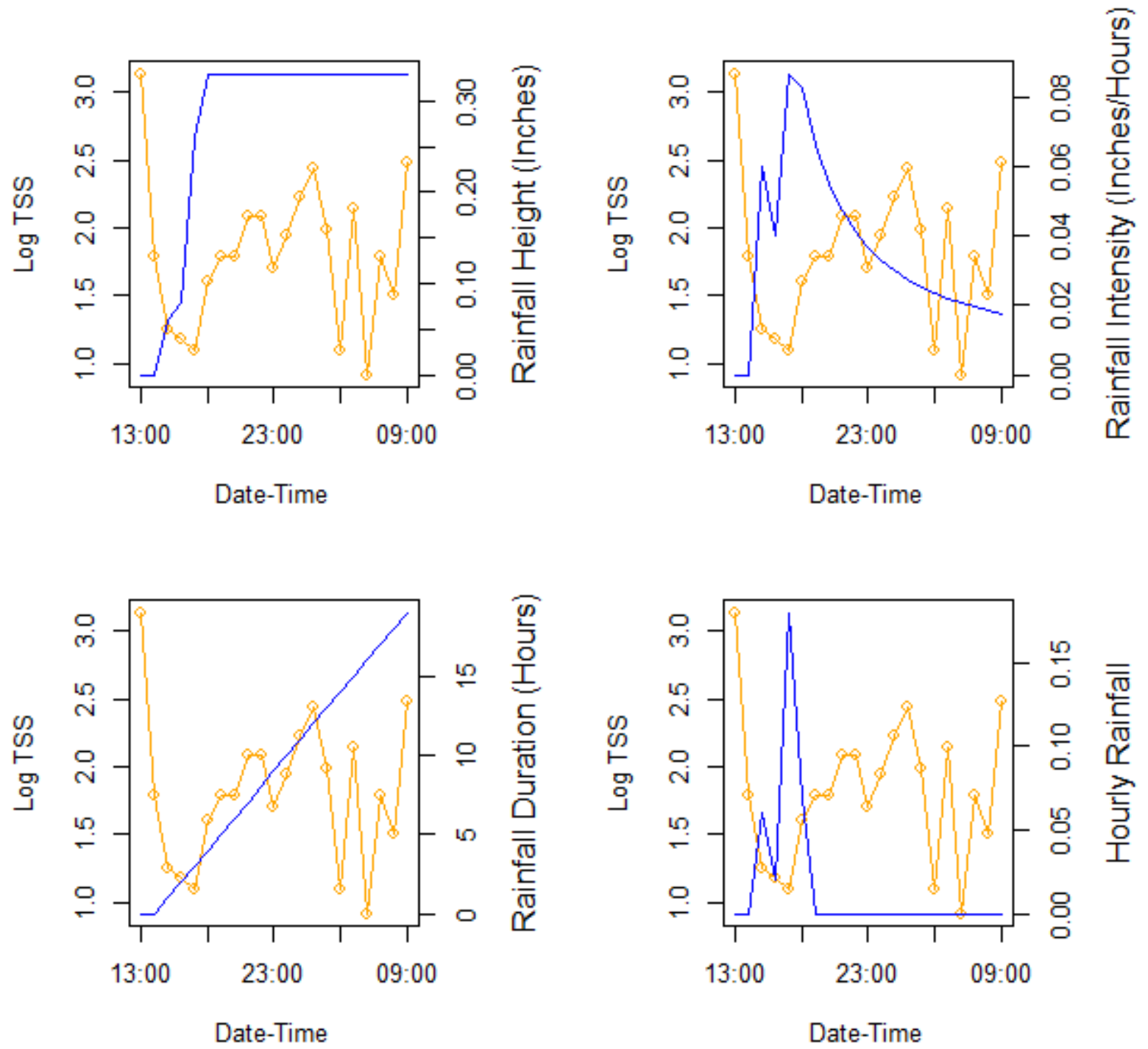

Figure A1: Log TSS vs RH, RI, RD, and Hourly Rainfall a storm on 3/3/17. The red line represents the $\log (43) \mathrm{mg} / \mathrm{L}$ TSS informal benchmark informed by BES and ODEQ. Note that none of the log TSS values were greater than the benchmark 


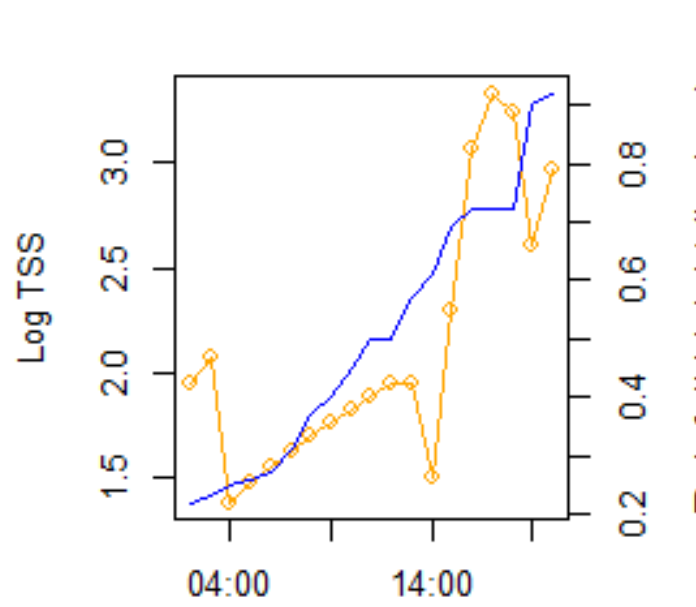

Date-Time

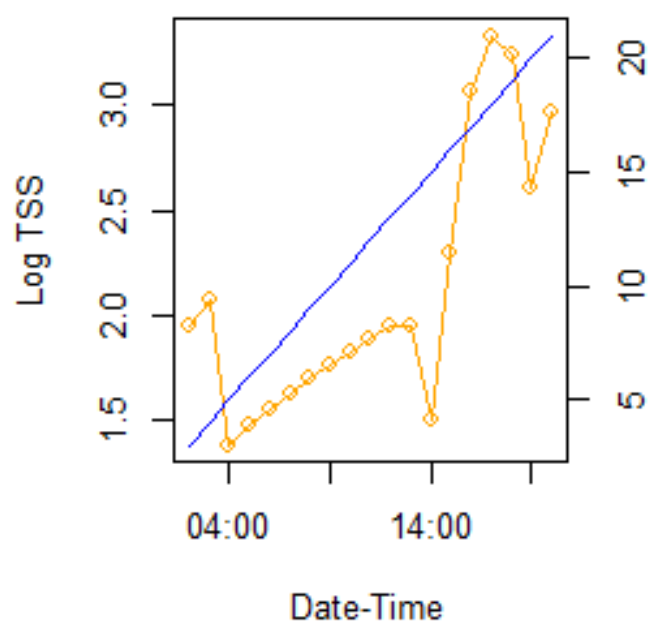



Date-Time

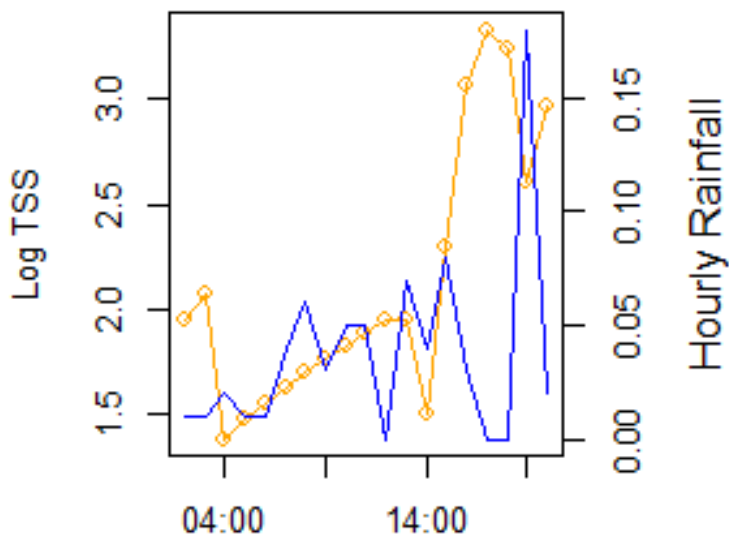

Date-Time

Figure A2: Log TSS vs RH, RI, RD, and Hourly Rainfall a storm on 3/9/17. The red line represents the $\log (43) \mathrm{mg} / \mathrm{L}$ TSS informal benchmark informed by BES and ODEQ. Note that none of the log TSS values were greater than the benchmark 

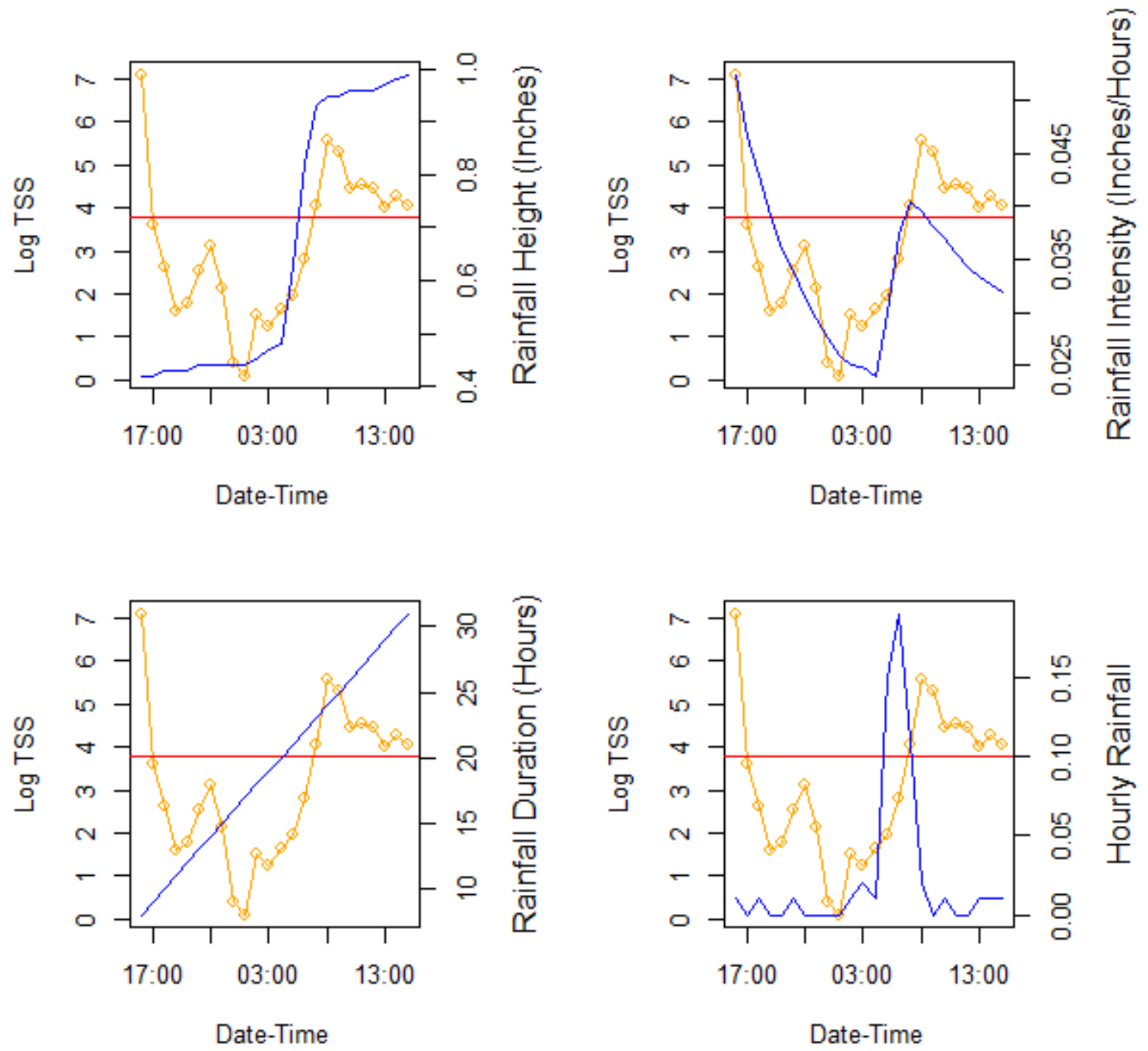

Figure A3: Log TSS vs RH, RI, RD, and Hourly Rainfall a storm on 3/17/17. The red line represents the $\log (43) \mathrm{mg} / \mathrm{L}$ TSS informal benchmark informed by ODEQ and PAWMAP. 

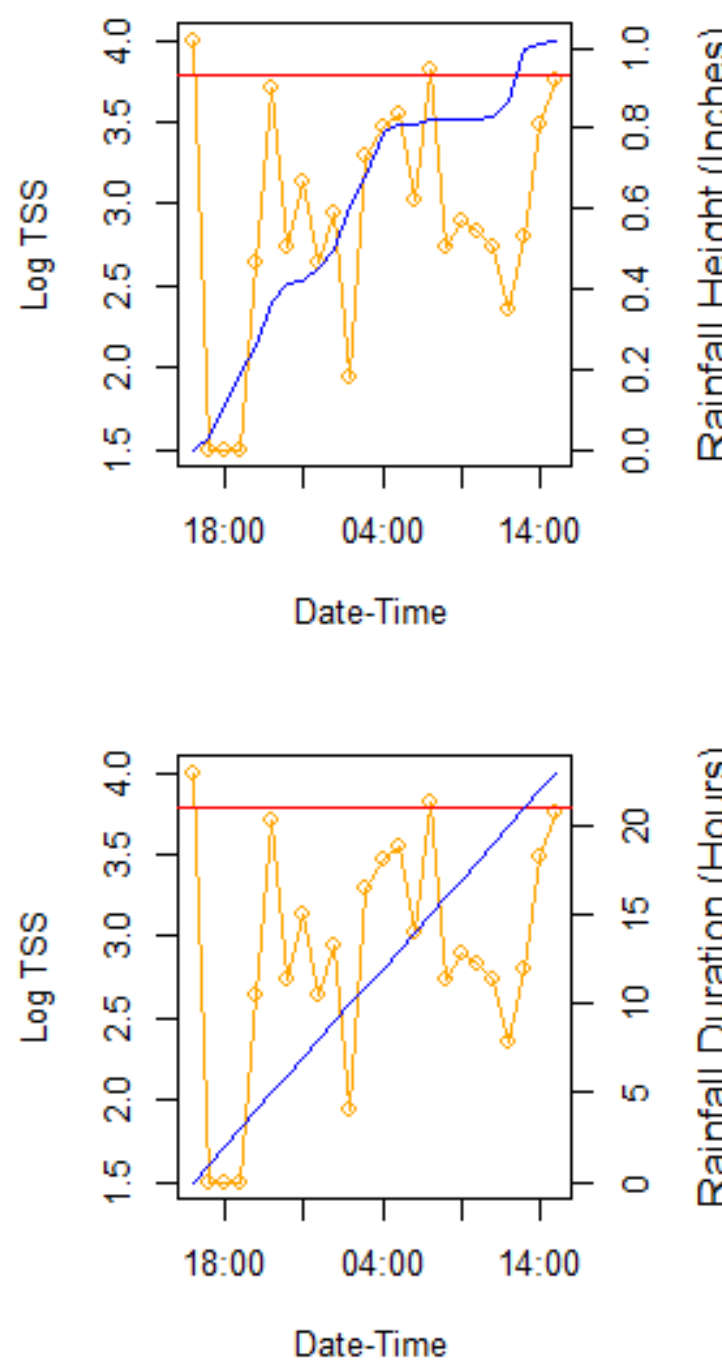

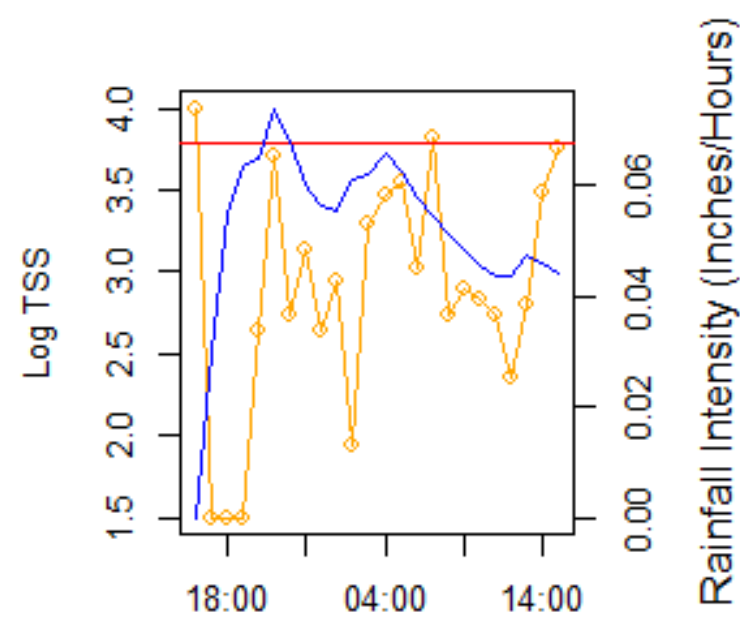

Date-Time

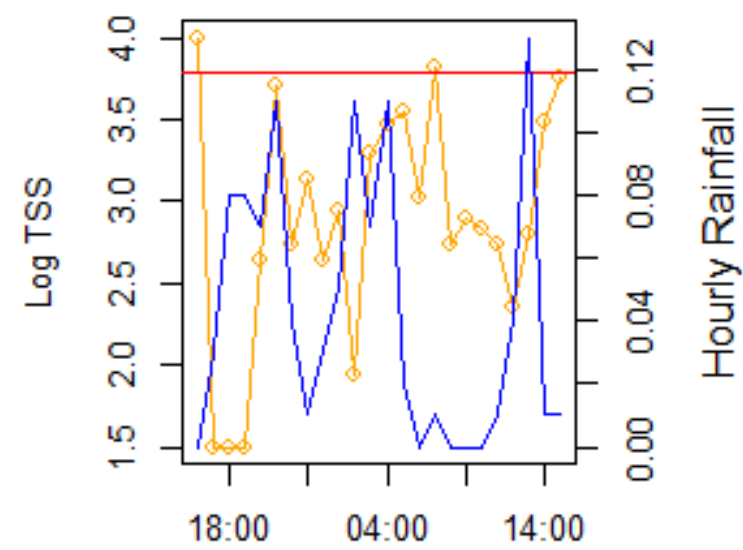

Date-Time

Figure A4: Log TSS vs RH, RI, RD, and Hourly Rainfall a storm on 3/23/17. The red line represents the $\log (43) \mathrm{mg} / \mathrm{L}$ TSS informal benchmark informed by ODEQ and PAWMAP. 

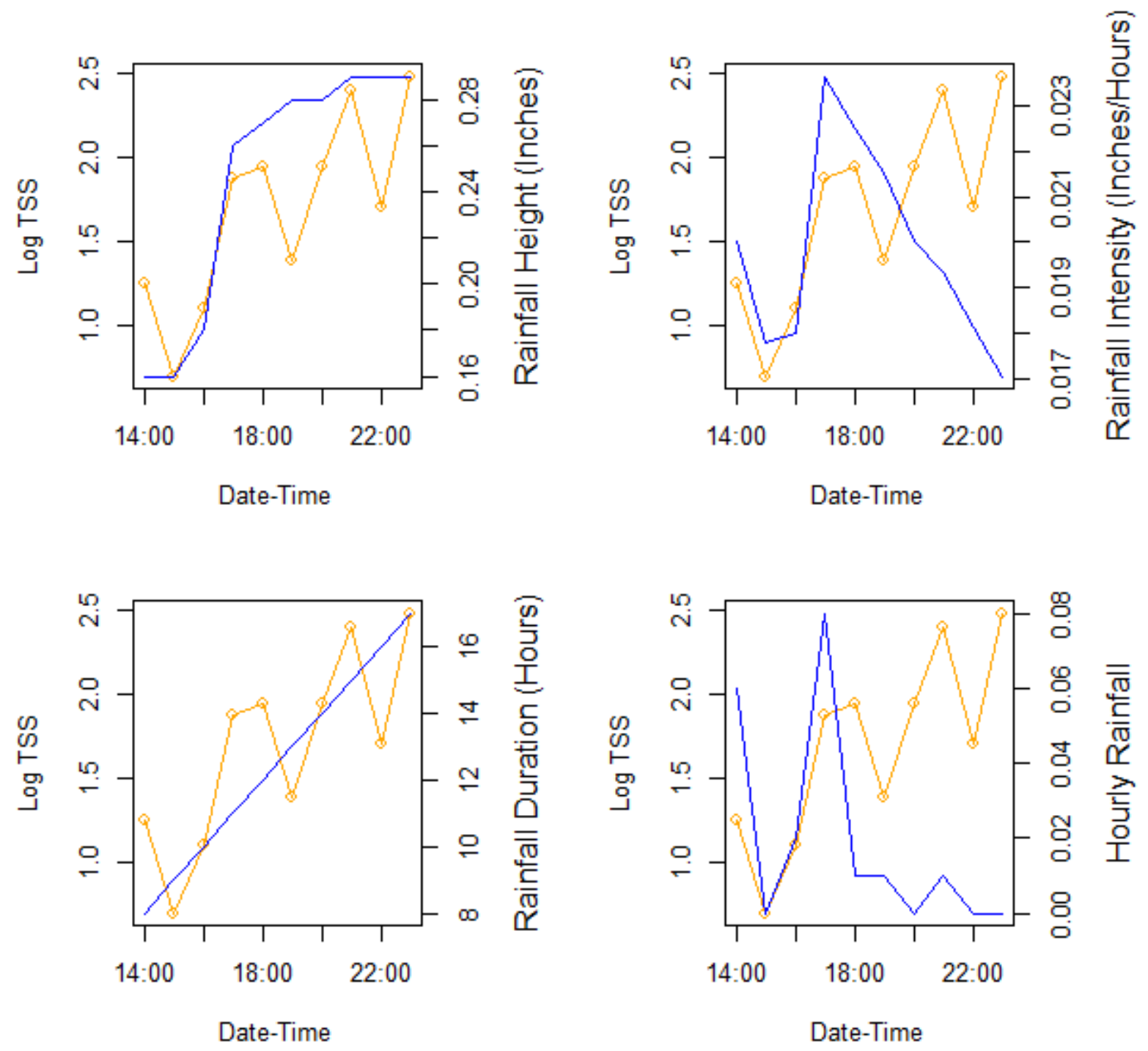

Figure A5: Log TSS vs RH, RI, RD, and Hourly Rainfall a storm on 4/19/17. The red line represents the log (43) mg/L TSS informal benchmark informed by BES and ODEQ. Note that none of the log TSS values were greater than the benchmark 

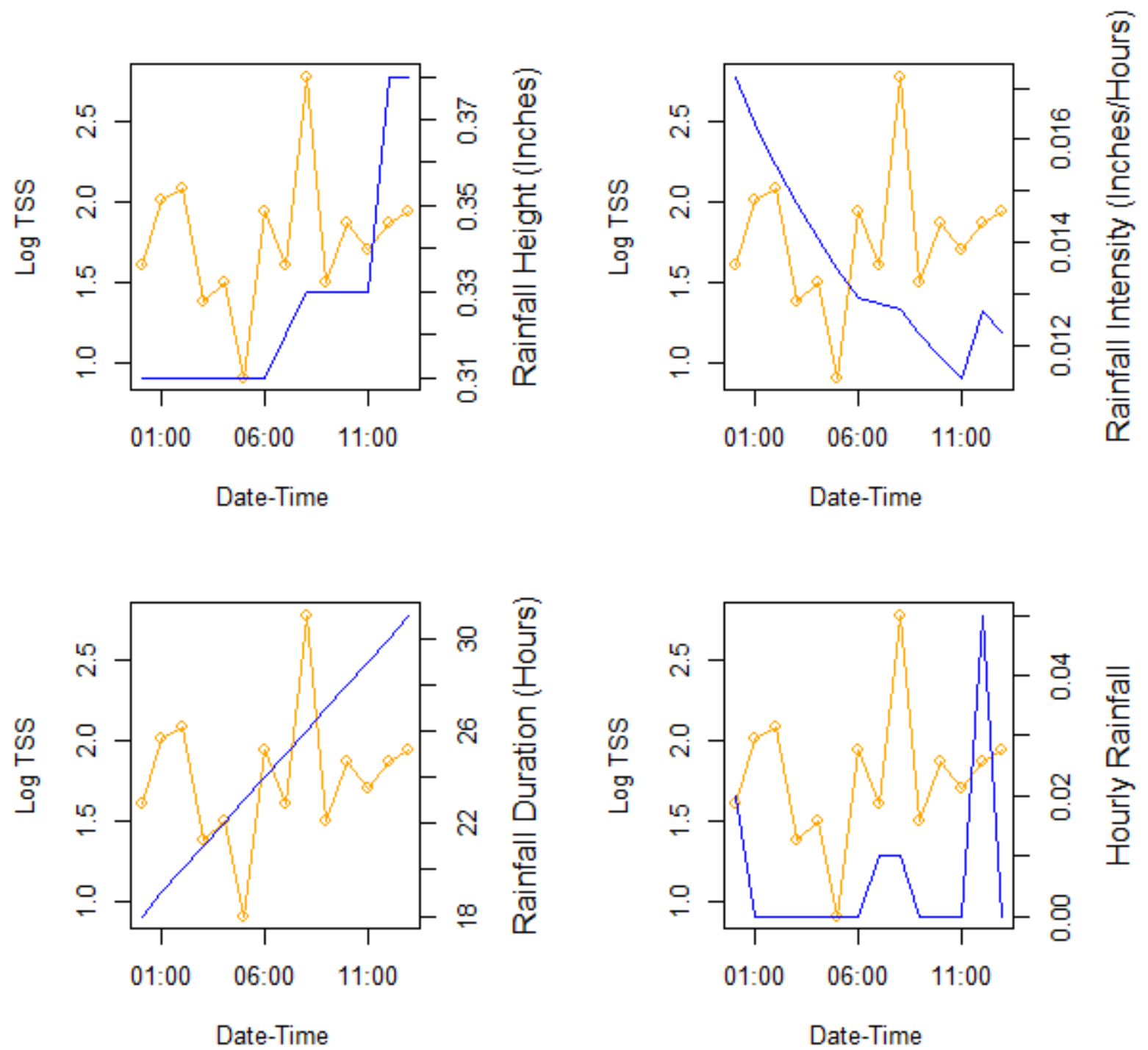

Figure A6: Log TSS vs RH, RI, RD, and Hourly Rainfall a storm on 4/23/17. The red line represents the log (43) mg/L TSS informal benchmark informed by BES and ODEQ. Note that none of the log TSS values were greater than the benchmark 